\title{
Geospatial Analysis and Mapping Strategies for Fine Grained and Detailed COVID-19 Data With Geographic Information Systems
}

\author{
ANGEL MIRAMONTES CARBALLADA ( $\nabla$ angel.miramontes@usc.es) \\ University of Santiago de Compostela: Universidade de Santiago de Compostela \\ https://orcid.org/0000-0003-1162-3329 \\ JOSE BALSA-BARREIRO \\ MIT Media Lab
}

\section{Research}

Keywords: SARS-CoV-2, CoVID-19, Geographic Information Systems, spatial patterns, territorial impact, mapping

Posted Date: March 4th, 2021

DOI: https://doi.org/10.21203/rs.3.rs-273514/v1

License: (c) (i) This work is licensed under a Creative Commons Attribution 4.0 International License. Read Full License 


\title{
Geospatial analysis and mapping strategies for fine-grained and detailed COVID-19 data with Geographic Information Systems
}

\author{
Miramontes Carballada, A. ${ }^{1}$ and Balsa-Barreiro, J. ${ }^{1,2}$ \\ ${ }^{1}$ Galician Studies and Development Institute (IDEGA), University of Santiago de Compostela, 15782 Santiago de \\ Compostela (Spain) \\ ${ }^{2}$ MIT Media Lab, 75 Amherst St, Cambridge, MA 02139, United States
}

Abstract

The CoVID-19 pandemic is showing a dramatic impact across the world. To the tragedy of the loss of human lives, we must add the great uncertainty that the new coronavirus is causing to our lives. Governments and public health authorities must be able to respond this emergency by taking the appropriate decisions for minimizing the impact of the virus. In the absence of an immediate solution, governments concentrate their efforts on adopting non-pharmaceutical interventions for restricting the mobility of people and reducing the social contact. Health authorities are doing public most of data that support their interventions and policies.

The geographic location of the cases is a vital information with exceptional value for analysing the spatiotemporal behaviour of the virus, doing feasible to anticipate potential outbreaks and to elaborate predictive risk mapping. In fact, a great number of media reports, research papers, and web-browsers have presented the COVID-19 disease spreading by using maps. However, processing and visualization of this sort of data presents some aspects that must be carefully reviewed. Based on our experience with fine-grained and detailed data related to COVID-19 in a Spanish region, we present a bunch of mapping strategies and good practices using geospatial tools. The ultimate goal is to create appropriate maps at any spatial scale while avoiding conflicts with data such as those related to patients' privacy.

Keywords

SARS-CoV-2, CoVID-19, Geographic Information Systems, spatial patterns, territorial impact, mapping

On $31^{\text {st }}$ December 2019, China reported a cluster of cases of pneumonia related to a novel coronavirus in the city of Wuhan in Hubei, mainland China. Twelve weeks later, on $11^{\text {th }}$ March 2020, the World Health Organization (WHO) declared a global pandemic originated by the severe acute respiratory syndrome coronavirus 2 (SARS-CoV-2), aka the novel coronavirus 2019-nCoV. Today, more than one year later, the virus has spread uncontrollably around the world, despite 
economic scenarios [1], being expected an impoverishment of large sections of communities and a substantial increase in social inequalities at all levels $[2,3]$.

39 The spread of the virus is explained by our individual and social behaviour. Many countries, especially the western ones, are having serious difficulties in containing the virus efficiently. The

41 decisions adopted by these countries face a complicated trade-off between to constrain the

42 individual freedom for moving from place to place and to preserve economic activities. National

43 strategies range from coexistence with the virus to its suppression (i.e., Zero COVID), being

44 referent the policies adopted by Sweden during the first wave and China.

45 Whatever the strategy adopted, the management of the pandemic has demonstrated the need to 46 manage mobility flows. The final objective is to reduce transmission, especially in vulnerable

47 groups of people, and optimize health resources until a potential vaccine or any other intervention

48 potentially successful could reduce the impact of the pandemic.

49 Any action or intervention against the virus requires knowing its spatio-temporal behaviour. For

50 this, it is necessary to anticipate the emergence of new outbreaks. In case of new infected people,

51 fast tracking of their movements and contact tracing is required for controlling the potential spread

52 of the virus. This process requires a fast and agile data management, taking into account the

53 incubation period of the virus (up to 14 days) and the relatively high percentage of asymptomatic 54 patients.

55 For addressing this emergency, governmental authorities and health managers establish special 56 protocols for sharing sensitive data in order to take decisions based on scientific criteria. The 57 geographical component of information (geodata) has become one of the most valued data for 58 understanding how the virus spreads across the territory. The use of Geographic Information 59 Systems (GIS) for mapping data may play a crucial role for fighting against infectious diseases 60 such as COVID-19 covering aspects in different steps related with the territorial impact of the 61 pandemic such the virus spreading, the contact tracing or the vaccine distribution, among others. 
62 These GIS systems can help to support authorities and policy makers in the implementation of 63 interventions against the virus.

64 There are more examples related with the importance of geospatial technologies during this 65 pandemic. The proliferation of web mapping applications and dashboards has become a pivotal 66 source of information during the COVID-19 pandemic, thanks to the combination of advanced 67 computer graphics and technologically innovative imaging solutions [4]. The dynamic 68 representation of information using these systems serves to inform and raise awareness in 69 society, as well as helping to manage uncertainty, while improving the governments and 70 authorities communication transparency. Mapping COVID-19 data in (near)-real time allows 71 delimiting risk areas, in addition to reduce the risk of exposure to the virus and support authorities

72 in decision-making. The most popular dashboards are the published by the Center for Systems

73 Science and Engineering at Johns Hopkins University [5] and the World Health Organization [6].

74 Both dashboards represent official data for countries and regions in near-real time (approx. every

$7515 \mathrm{~min})$. Another dashboard, HealthMap [7], uses online media data sources for real-time 76 surveillance with a higher level of spatial resolution in some countries..The importance of 77 geolocation technologies goes beyond. These may potentially be used for other virus-related 78 tasks such optimised placing for emergency treatment units and basic resources in critical 79 situations, enabling to ensure the supply chain and distribution of equipment and resources [8]. 80 China and other countries have also used drones for logistics distribution or surveillance tasks 81 during the pandemic, especially at times when it has been necessary to reduce human contact 82 [9]. Integrated drone and GIS technologies allow to optimize efforts especially in those areas that 83 need it most. This is particularly important in urban areas due to the high concentration of people 84 and features, which increases the levels of risk. In these areas, it is required a very detailed 85 mapping based on high-precision three-dimensional models [10].

86 Web app/platforms for tracking people allows to estimate mobility of infected and vulnerable 87 people in each moment. Thus, it is possible to rebuild spatial patterns of the virus and to propose 
adequate interventions for risk mitigation. Many countries have developed their own web

89 app/platforms although with different success rates such as Close Contact Detector in China [11],

90 Trace Together in Singapore [12], COCOA in Japan [13], SwissCoVID in Switzerland [14] or

91 RadarCoVID in Spain [15].

92 All the previous examples show the importance of spatial analysis methods to understand the

93 disease spread process, enabling to identify new outbreaks and spatial patterns. In addition, these

94 allow to combine these data with the sociodemographic and environmental characteristics of the

95 territory, achieving a holistic perspective of the actual impact of the disease [16]. Thus, it is

96 possible to anticipate the future behaviour by developing models for predictive risk mapping based

97 on computerised spatial analyses that integrate different calculation algorithms [17].

98 Paradoxically, the COVID-19 has become a great opportunity for the development and

99 implementation of geospatial analysis for decision-making in emergencies [18]. The exponential

100 increase in computing capacity for information processing, especially within GIS tools, is

101 substantially improving our response capacity to emergencies like the current one. However, in

102 the face of this boom of geospatial analysis, certain shortcomings related to the implementation

103 of adequate strategies for mapping and processing geodata must be analysed.

104 The case study presented here is carried out in the region of Galicia, located in NW Spain.

105 Precisely, Spain is one of the worst severely affected countries by the COVID-19. At a global

106 scale, Spain is one of the most affected countries by COVID-19 (see Section 4.1). The sub-optimal

107 national response to the COVID-19 pandemic has been widely criticized by relevant health

108 management leaders and experts at a national scale [19]. In subsequent editorials of The Lancet,

109 this group of leaders and scientists referred to the weakness of the so-called test-trace-isolate

110 tryptic for explaining the imminent impact of the second wave. They made an urgent appeal to

111 the authorities to publish accurate and detailed data on the virus' incidence [20, 21], which would

112 facilitate the better understanding of the virus and to respond adequately to new outbreaks. 
113 This case study counts with accurate and detailed fine-grained data related to all the officially

114 registered cases of COVID-19 in the region of Galicia. These data include the residential address

115 of each case, being possible to display our data at the highest spatial scale. Our objective with

116 these data is to raise and to analyze adequate mapping strategies for enhancing the data value

117 while avoiding conflicts and deficiencies related with the use of these data. The most important

118 aspects related are presented and discussed later.

119 This paper is structured as follows. Section 2 provides a comprehensive literature review on how 120 mapping has been used in the study of infectious diseases in the past and is being used in the 121 current pandemic. Section 3 presents the work methodology. Section 4 introduces the study area 122 and describes the dataset. Section 5 presents some visual results in form of maps. Section 6 123 discusses the previous results and other relevant aspects related to this research. Finally, we 124 summarize the most relevant points presented in this paper.

\section{Literature Review}

127 Throughout human history, emerging and re-emerging infectious diseases threaten humankind.

128 These diseases can transform themselves in epidemics when the rapid spread of disease to a 129 large number of people in a given population within a short time lapses. Spatial spread depends 130 on the disease mechanism, human mobility, and control strategy [22]. Understanding their high 131 spatio-temporal behavior requires an exhaustive observation of their spatial patterns, which are 132 due to a complex set of interactions between human and environmental factors [23], showing 133 large regional differences.

134 The territorial factors behind the impact of diseases presents a tradition within the health 135 geography. According to Kearns and Moon [24], this sub-discipline presents a predominantly 136 utilitarian perspective by analyzing the territory technically, although it incorporates structuralist 137 approaches, such as cultural and sociological vision of social welfare, a sense of place for people, 138 and a critical stance. In recent decades, it is more frequent the compilation of maps for assessing 
139 the territorial impact of certain diseases. Examples are the Atlas of Cancer Mortality in China [25] 140 and in the United States [26]. These studies display incidence data, while other ones that are 141 more recent are focused on determining levels of risk or identifying spatial patterns [27]. As 142 examples, Castronovo, Chui and Naumova [28] analyzed the spatio-temporal dynamics of 143 salmonella infections for 2002 in elderly people in the United States, while Mohd, Jacobsen and 144 Wiersma [29] established risk maps of hepatitis A virus at a global scale.

145 Maps have become essential tools for understanding and tracking infectious diseases. One of the 146 first infectious disease maps was carried out in 1694 on plague containment in southern Italy [30].

147 Although probably, the notorious John Snow's map on the 1854 cholera outbreak in London is 148 the best known example to illustrate the power of mapping in public health [31]. There is a large 149 recent literature regarding studies on mapping and spatial patterns of infectious diseases. A 2014 150 review of the health GIS literature found that 248 out of 865 focused on infectious disease 151 mapping [32]. Wahid et al. [33] analyzed the spatial spread of the Chikungunya virus, a mosquito152 transmitted alphavirus, since the first was reported in Tanzania in 1952. It has since spread across 153 the entire globe causing large numbers of epidemics that have infected millions of people in Asia, 154 India, Europe, the Americas, and Pacific Islands. Pigott et al. [34] assembled location data on all 155 recorded zoonotic transmission to humans and Ebola virus infection in bats and primates since 1561976 to 2014, predicting a transmission niche in different countries across Central and West 157 Africa. Their study showed how despite 22 million people inhabit regions at risk, the rarity of 158 human outbreaks emphasizes the very low probability of transmission to humans. Cattarino et al. 159 [35] developed a high-resolution global map on the intensity of dengue spread by adapting 160 geospatial models based on the environment. Samy et al. [36] studied the recent outbreaks of 161 Zika, a new virus discovered in Uganda in 1947 that is transmitted by aedes mosquitoes. They 162 studied spatial spread of Zika in South America, addressing urgent knowledge gaps regarding 163 drivers of transmission and the global potential for spread this virus. Messina et al. [37] showed 164 how large portions of tropical and sub-tropical regions globally have suitable environmental 
conditions for the Zika virus with over 2.17 billion people inhabiting these areas. The list is much more extensive, with a bunch of studies analyzing the impact of other viruses in certain regions.

167 Reeves, Samy and Peterson [38] carried out a first detailed geographic and environmental study 168 of MERS-CoV distributions across the Middle East, Deka and Morshed [39] analyzed the spatial 169 spread of Nipah virus in South and Southeast Asia, while Sánchez-Gomez et al. [40] did the same 170 with West Nile virus in Spain.

171 The complexity of human and environmental interactions explains the magnitude of epidemics. 172 GIS tools and the estimation of spatial statistics may help mitigate the epidemic through scientific 173 information, finding spatial correlations with other variables and identifying transmission dynamics $174[41,42]$. GIS tools favors a dynamic mapping based on simultaneous visualization of temporal and 175 spatial information, enabling to evaluate the complex interactions between humans and 176 environment [28]. To cite only a few examples, Grantz et al. [43] showed how living in census 177 tracts with higher illiteracy rates increased the risk of influenza and pneumonia mortality during 178 the influenza pandemic of 1918 in Chicago. Allcott et al. [44] evaluated the relationship between 179 COVID-19 reported cases and the compliance level to containment measures against the virus in 180 American counties. The recent implementation of GIS for disease mapping and correlated factor 181 is detailed in some recent studies. Parks, MacDonald and Beiko [45] used an automated pipeline 182 to collect data for analysis in the geospatial package GenGIS, which allows the geographic and 183 temporal tracking of new sequence types and polymorphisms related to 2009 swine-origin strain 184 of influenza $A(H 1 N 1)$. Giyonko et al. [46] analyzed the epidemiological role of camels in the 185 transmission of MERS-CoV virus by implementing an iterative empirical process in GIS to identify 186 and qualify potential hotspots for maintenance and circulation of this virus. Fuller et al. [47] 187 identified those areas where reassortment events might occur and how high pathogenicity Avian 188 Influenza virus might travel if it enters wild bird populations in the United States.

189 Similarly, geospatial tools are already playing a key role in the current COVID-19 pandemic. 190 These are used for aggregating big data from multiple sources, intuitive visualizations and maps, 
spatially tracking confirmed cases, predicting regional transmission, balancing and managing

192 supply and demand for material resources, which provided strong spatial information support for 193 decision making, formulating measures and evaluating the effectiveness of prevention and control 194 of COVID-19 cases [48]. Some recent studies evaluate the territorial impact of COVID-19 at 195 different spatial scales [49,50]. A cross-sectional approach shows an association between the 196 accelerated diffusion of the virus and high air pollution and low wind speeds [51]. Oto-Peralías 197 [52] conducted a multifaceted study by combining geographical and socio-economic variables to 198 explain the large disparity of infected people between Spanish provinces. He found interesting 199 correlations with temperature and distance from Madrid, the capital city, during the first wave.

200 The importance of the spatial dimension for disease mapping forces us to rethink certain relevant 201 aspects to display cartographic information. In this regard, Cicalò and Valentino [4] introduced 202 new approaches aimed to visualize, describe and explain spatial patterns of diseases. One of the 203 most critical aspects is to define a scientific geographic unit for health-care market for analysis 204 and visualization [53]. It will depend on the spatial scale and the level of aggregation of data. 205 Thus, in the past it was more frequent to constrain to nearby environments. Tuckel et al. [54] 206 studied the diffusion of the Influenza pandemic of 1918 in Hartford, Connecticut, United States, 207 while Smallman-Raynor, Johnson and Cliff [55] did the same in London and the county boroughs 208 of England and Wales. Nowadays, some studies limit the scope to much reduced events such as 209 Rodriguez-Morales et al. [56], which studied a recent Zika virus outbreak in Valle de Cauca, 210 Colombia. Nowadays, the high computational capacity of GIS tools makes it possible to expand 211 the study to all spatial scales. The first studies about COVID-19 were conducted at national scale, 212 although over time was more possible to carry out studies at more spatial scales (such counties 213 or provinces), but always with aggregated data. 


\section{3. Methodology}

217 We represent fine-grained health data associated with COVID-19 in the Spanish region of Galicia.

218 These data contain individual and precise information on each case, including its residence

219 address. It allowed to achieve a very accurate picture of the virus' spread within this region. These

220 data were provided by regional health authorities in order to reach a better understanding of the

221 spatial behaviour of the virus and to implement the adequate interventions for minimizing the 222 impact derived.

223 In this paper, our objective is to raise different mapping strategies potentially valid for health

224 management authorities. Maps may be used as crucial tools for identifying spatial patterns of the 225 virus, constraining the virus, but also for checking if the interventions and policies adopted are 226 working. Different mapping strategies are proposed by considering the multiscalability of data, the 227 level of aggregation of data, and data privacy's concerns.

228 The strategies and methodologies for mapping these data must be valid for promoting the 229 integration of multidisciplinary working teams, including professionals without any expertise in 230 cartography. The potential of our results must facilitate the review, analysis, and interpretation of 231 data enabling to identify potential risks and to take informed decisions by policymakers and 232 authorities.

\section{4. Data and study area}

235 Here below our study area and the data used are presented. For this, this section is organized as 236 follows. Initially, sub-section 4.1 contextualizes the impact of the pandemic at a national scale. 237 Sub-section 4.2 introduces our study area based on two aspects: (a) its sociodemographic reality 238 and (b) the impact of the pandemic according to the official statistics at a regional scale. Finally, 239 our dataset is presented in sub-section 4.3. Incidence data related to COVID-19 are obtained 240 from officially responsible institutions at national [57] and regional [58] scale. 


\section{$241 \quad$ 4.1. The Spanish context}

242 The novel coronavirus $2019-\mathrm{nCoV}$ entered Spain on $31^{\text {st }}$ January 2020, although no community 243 spread was detected until early March. On 14 ${ }^{\text {th }}$ March the national authorities imposed a harsh

244 lockdown with hard mobility restrictions and a forced halt to most labour activities. At that time, 245 Spain counted 6,332 infected cases and 193 deaths. The lockdown lasted 49 days, followed by 24648 days in which most of restrictions were progressively eased until the end of the first wave. The 247 balance of this first wave, as of $21^{\text {st }}$ June, was 246,504 infected cases and 28,313 deaths.

248 Sadly, Spain is one of the most affected countries in the world. It was European country in living 249 a second wave, counting a high number of cases in late summer. As of $15^{\text {th }}$ November, Spain 250 counted with 1.44 million reported cases, about 80,000 of them health-care workers. The number 251 of deaths caused by the virus stands at 40,460 , about 22,300 of them in nursing homes. Spain is 252 the 6th country with more reported cases and the 9th country with more deaths at a global scale.

253 It shows a fatality ratio of 2.8 deaths every 100 confirmed cases and 86.6 deaths per 100,000 254 inhabitants, one of the highest in the world after Belgium (121.6) and Peru (109.51).

255 But these data could be even worse. According with the tables reporting excess mortality [59], 256 actual number of deaths could be a third higher [60]. The seroprevalence studies carried out 257 during the first wave, between $27^{\text {th }}$ April and $11^{\text {th }}$ May, estimated that only $5 \%$ of Spaniards had 258 suffered the disease. These studies demonstrated substantial geographical variability, with higher 259 prevalence around Madrid (> 10\%) and lower in coastal areas $(<3 \%)$ [61]. 


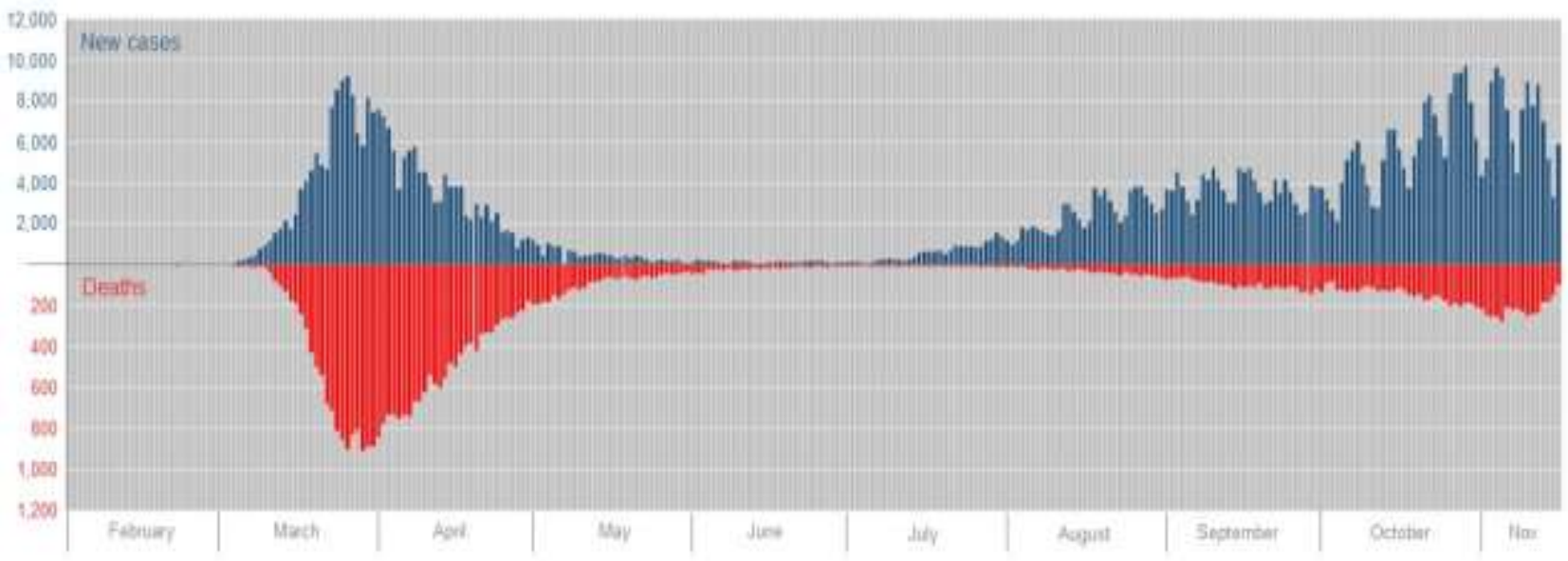

Figure 1. Number of reported cases and deaths from CoVID-19 in Spain since the beginning of the pandemic ( $31^{\text {st }}$ January) until $15^{\text {th }}$ November. Reported cases are shown in blue (Y-axis) and deaths in red ( $Y$-axis inverted).

\subsection{Our case study area: The region of Galicia}

Firstly, we present our study area by describing its sociodemographic reality (4.2.a). It will give us some important insights related to the spatial pattern of the virus. After that, we will check the impact of the pandemic according to the officially reported numbers (4.2.b).

\section{A) Geographical context}

271 Our study area corresponds to the region of Galicia, which is located in northwestern Spain. This 272 region has a population of 2.7 million inhabitants (6.1 percent of the Spanish population) and an 273 area of $29,575 \mathrm{~km}^{2}$ (5.8 percent of the Spanish area). Its population density is 91.3 inhabitants 274 per square kilometre [62]. It is administratively divided into four provinces, and 313 municipalities, 275 which correspond to local government units (third level of administration).

276 This region is characterised by the high dissemination of its population throughout the territory. In

277 fact, around half of the human settlements in Spain are located in this region, which is around 278 eight times more comparatively than its demographic weight at a national level [63]. In the last 279 few decades, its traditional population model is in crisis, with more people living in a very reduced 280 number of towns or cities. Nowadays, most of its population live next to the so-called Atlantic Axis, 
281 where the major and most thriving cities are located. Five of the seven main cities of this region 282 are located along this axis. Vigo and A Coruña are the two most important cities in the region with 283 approximately 300,000 inhabitants. The rest of the major cities concentrates around 100,000 284 inhabitants, with the exception of Pontevedra and Ferrol, which are less populated. From an urban 285 perspective, Galician region barely had intermediate urban referents with population between 28630,000 and 100,000 inhabitants. However, in very recent years, some municipalities located in 287 the suburban area of the most important cities (such as Narón, Arteixo, Ames, etc.) together with 288 the decline of some traditional cities (Ferrol) has led to a recent emergence of an increasingly 289 numerous group of intermediate cities.

290 The urban structure of this region is hierarchically dominated by the western part. Except for some 291 rare cases, with some exceptions [64], this area presents positive demographic patterns both 292 from a quantitative (higher rates of fertility, positive migratory balances) and a qualitative (less 293 aged population) perspective. The opposite trends are observed in the eastern part where the 294 two main urban referents concentrate a large part of the socioeconomic activity of their whole 295 provinces. The rest of the territory is dominated by a group of head towns, with a great influence 296 in large rural areas. 


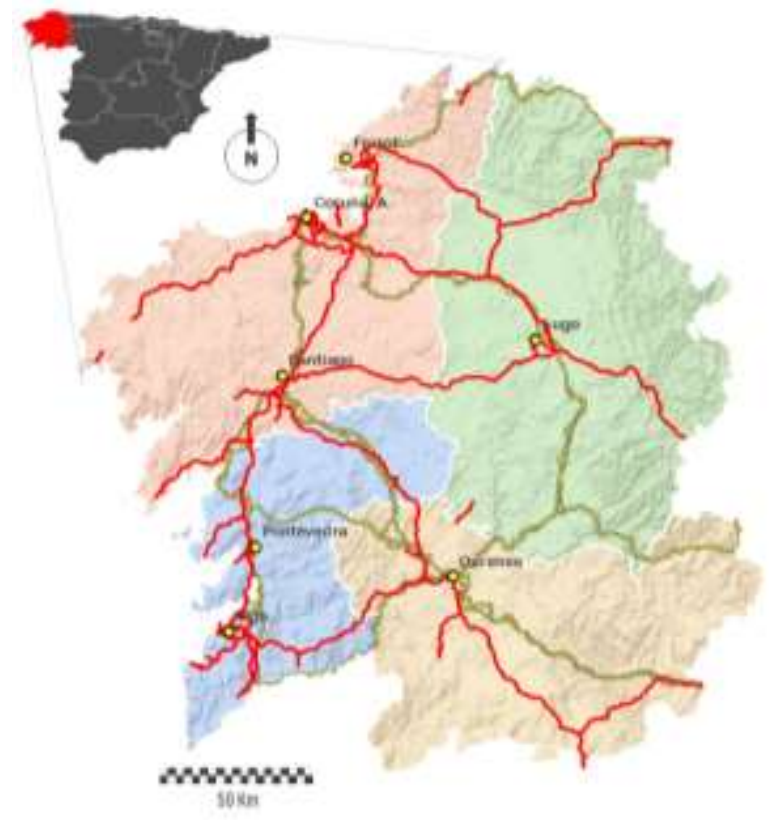

(a)

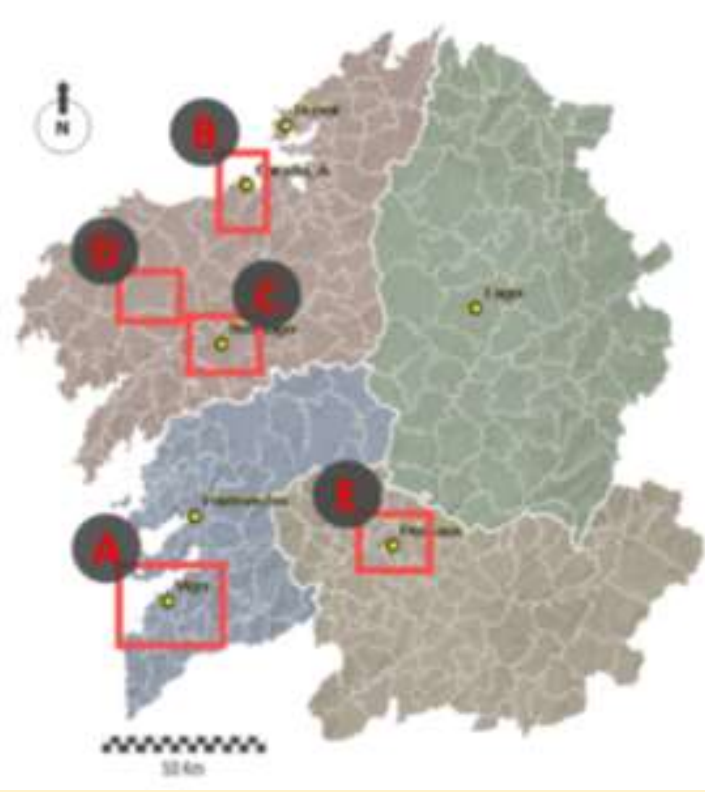

(b)

307 Figure 2. (a) The region of Galicia within Spain. The four background colours corresponds to provinces. The nodes in yellow, labelled with their respective names, represent the seven main cities. In this figure, it is also represented the main road networks, i.e. motorways/highways (red lines) and railways (yellow lines). (b) The sample study areas analyzed in section 5 are located and bounded by the red boxes.

\section{B) Incidence of CoVID-19}

315 As of $15^{\text {th }}$ November, Galicia reported 43,714 cases, 5,783 hospitalised, 661 attended in intensive

316 care units, and 1,084 deaths by COVID-19. Comparatively, these data represent $2.9 \%$ of the

317 cases and $2.6 \%$ of the deaths registered in Spain. The ratio of cases per 100,000 inhabitants is

318161.9 , and 4 deaths per 100,000 inhabitants. The fatality rate is 2.5 deaths per 100 reported cases

319 and 40.1 deaths per 100,000 inhabitants.

320 The results of the first wave, on $15^{\text {th }}$ June, showed a total of 10,489 infections and 619 deaths.

321 The fatality rate was 5.9 deaths per 100 reported cases and 22.3 deaths per 100,000 inhabitants.

322 The seroprevalence study carried out by the Galician government during the first wave estimated

323 that only $1.15 \%$ of its population had been infected, being one of the least affected regions in 324 Spain. 


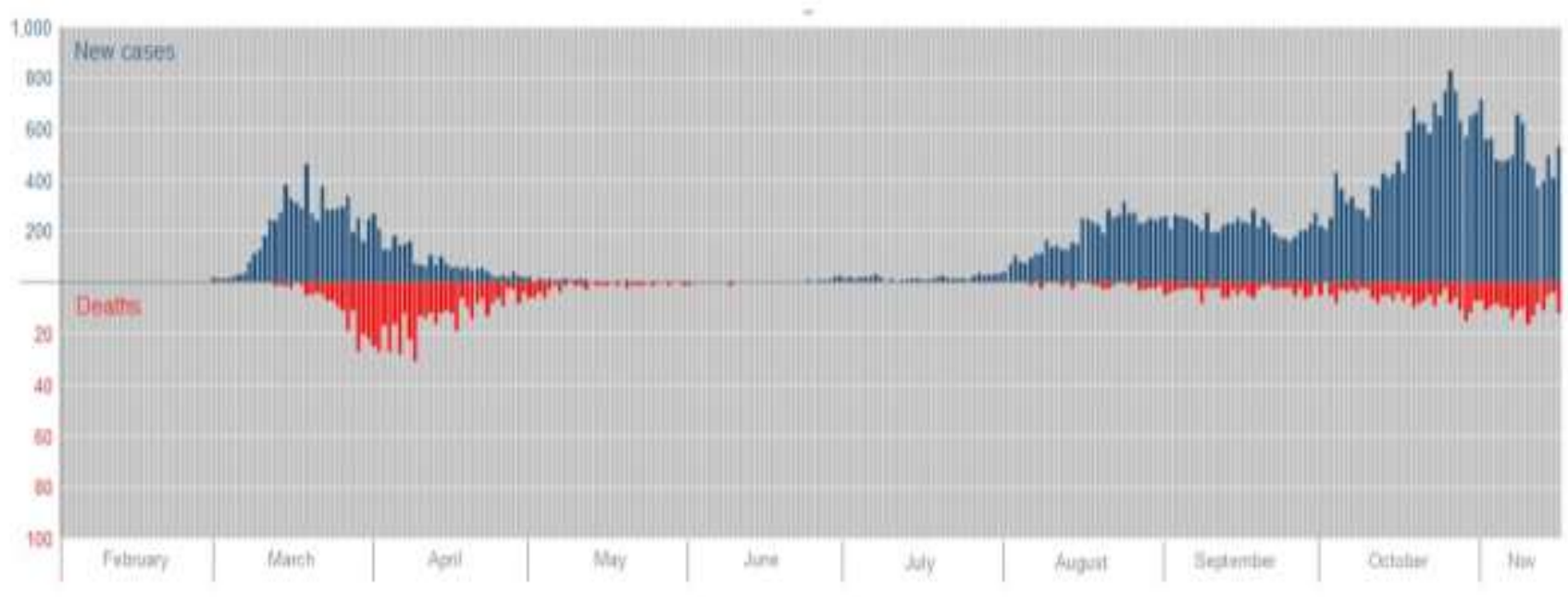

Figure 3. Number of reported cases and deaths from CoVID-19 in Spain since the beginning of the pandemic ( $31^{\text {st }}$ January) until $15^{\text {th }}$ November. Reported cases are shown in blue ( $Y$-axis)

\section{4.3. Data}

330 The dataset we will work on corresponds to all the individual cases reported in this region during 331 the first wave of the pandemic, ranging between $1^{\text {st }}$ March and $15^{\text {th }}$ July, 2020. This dataset 332 includes information related to all the cases officially reported by the Galician Health Service 333 (SERGAS), the health management authority in this region. This dataset counts with 11,070 334 records, 581 more cases than those officially published. This excess data amount mostly 335 corresponds with false positives.

336 Among the information included in the dataset, we count with bio data, place of residence, relevant 337 dates, and some indicators that allows to check a complete follow-up of the disease for each 338 reported case (i.e. home bound/hospital admission/death). Given that mobility was mostly 339 restricted by the lockdown, the great majority of cases can be we can spatially and temporally 340 delimited because dates related to symptoms and testing were recorded by the health workers.

341 The place of residence for each reported case is defined by its official address, which allow us to 342 obtain a very accurate representation of the spatial behaviour of the virus. 


\section{Results}

345 The first step was to apply a pre-processing of data in order to eliminate wrong and duplicate data 346 and adapt the structure and format of all the data. After that, we georeference the whole dataset

347 using the API tool implemented in the software ArcGis. Each record is represented as a point 348 entity that is spatially located based on the address field. In short, 10,853 records were located, 349 which corresponds to the 98 percent of total.

350 Mapping addresses by dots give us a good approach to understand the spatial patterns drawn by 351 the virus in this region. Most of these dots are concentrated close to the most important cities, 352 especially along the Atlantic shoreline (Figure 4.a). Depending on the scale, the interpolation of 353 these points in a raster map may facilitate a clearer and more intuitive identification of these spatial 354 patterns. Figure 4.b shows a heat map where the point density is represented. The red-coloured 355 areas represent the most affected areas by the virus, while the green-coloured areas the least 356 ones. The degradation between the previous colours (i.e., mostly yellow tones) represents those 357 areas with an intermediate level of cases.

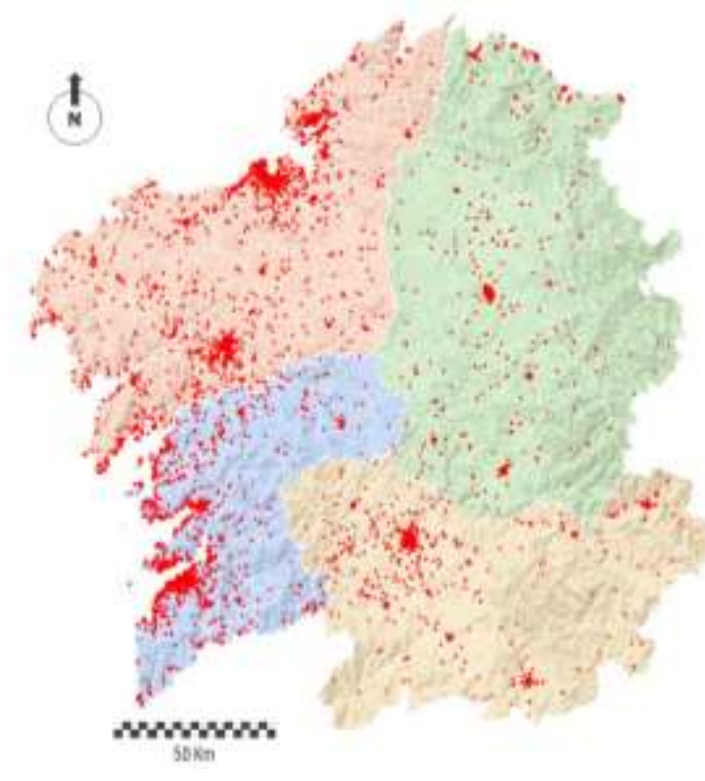

(a)

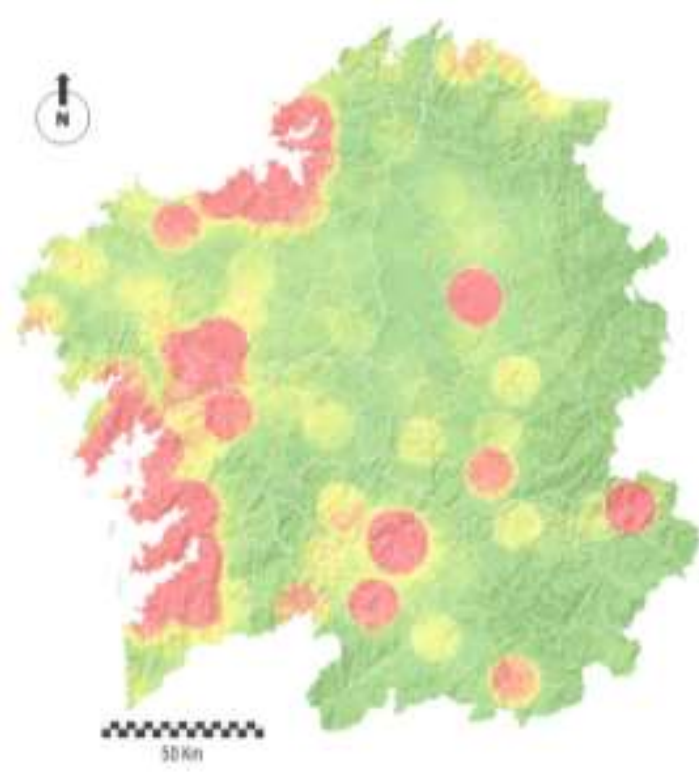

(b)

358 Figure 4. Mapping COVID-19 cases officially reported in this region. (a) Representation of the 359 most fine-grained level of detail. In this map, each single red dot corresponds to a reported 
case, which is spatially located based on the private address. (b) Mapping using a heat map, where areas with the highest point densities corresponds to the areas in red. Raster composed of 358 columns and 323 rows, with a cell size $1000 \times 1000$.

A more detailed approach to the virus spreading is computing some relevant rates. This sort of rates is represented by choropleth maps, where each region is colour-shaded according to different value intervals. We estimate the density COVID-19 cases in relation to total population and total surface. Figure 5.a represents the number of COVID-19 cases per inhabitant, while Figure 5.b represents the number of COVID-19 cases per square kilometre. Both figures are

370 level.

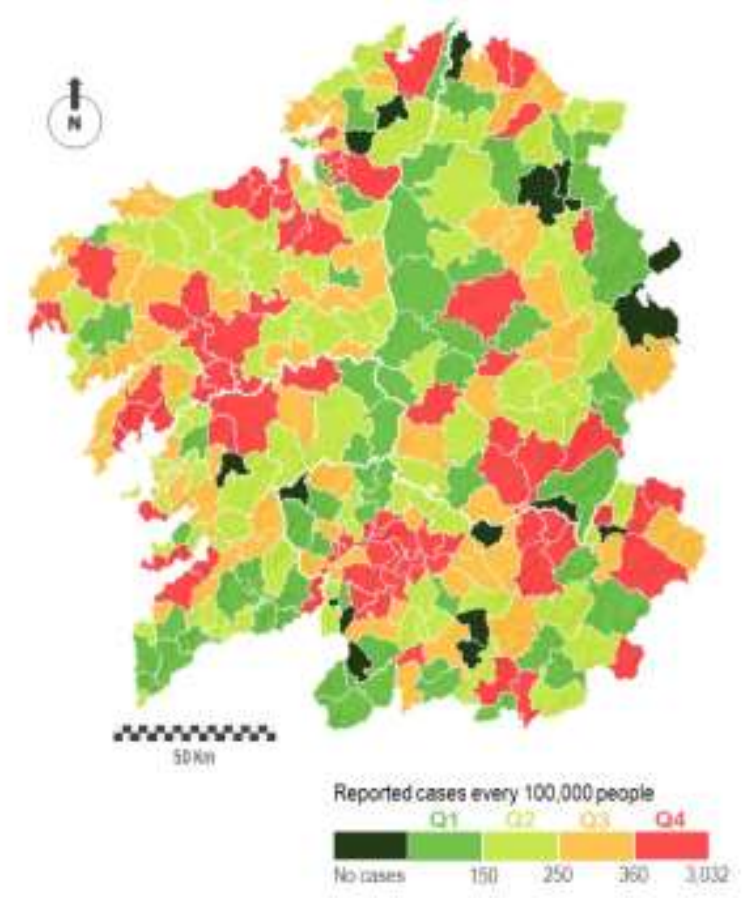

(a)

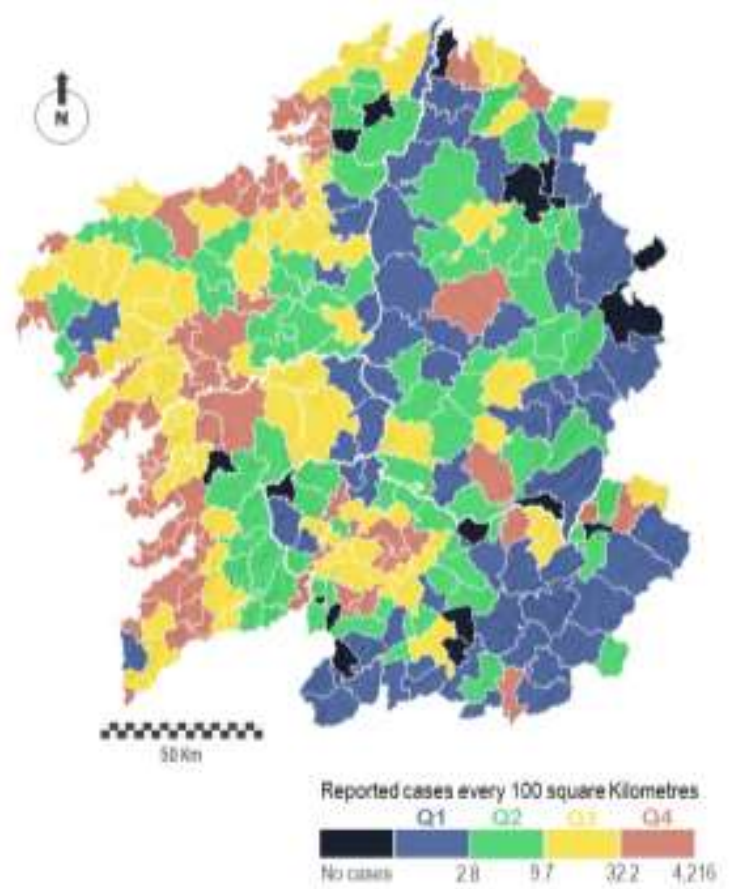

(b)

Figure 5. Mapping COVID-19 cases officially reported at a local scale of aggregation (municipalities). (a) Number of cases per 100,000 inhabitants. (b) Number of cases per 100 $\mathrm{km} 2$. In both cases, the intervals are distributed in regular quartiles.

The COVID-19 cases' density by surface presents a very similar spatial pattern to the previous figures, where municipalities with a higher density of reported cases are located along the Atlantic Axis. However, the map of density of reported cases by population shows a spatial pattern quite 
378 different. We can observe some groups of municipalities in the inner region showing the highest 379 values for the whole region. In addition, we are able to clearly distinguish in both maps how some 380 large areas were not affected at all by the virus. In fact, 18 municipalities (5.7 percent of the total), 381 mostly located in the eastern part, did not report any case.

382 The complexity of the territory explains why COVID-19 cases' distribution is spatially 383 heterogeneous. Thus, we must analyze data at multiples spatial scales, as shown below. Figure 384 6.1.a represents the spatial distribution of reported cases at a municipal level. This figure allows 385 to discern a clear dichotomy between the municipalities located at the western and eastern 386 sectors. However, zooming into the map we can observe how this spatial pattern is clearly fractal. 387 Figure 6.1.b corresponds a small selection of the municipalities surrounding Vigo, the most 388 populated city in this region with about 300,000 inhabitants. This area is located in the southern coast and it corresponds to the study area A in Figure 2.b. According to the map legend, all these municipalities were one of the most affected by COVID-19 at a regional scale.

391 Figure 6.2.a represents an internal distribution of reported cases at a lower level of spatial 392 aggregation for the municipality of Vigo. This aggregation level corresponds to census districts. 393 In total, the municipality of Vigo holds 236 census districts, whose size varies substantially 394 depending on factors such as the resident population. The smallest census districts are located 395 in the consolidated urban area, while the largest ones are located on the periphery. From the 396 perspective of the virus spreading, we can refer to some relevant aspects. The majority of the 397 most affected districts (red-coloured in the map) are located in the city area. But not all of them 398 are located in the downtown, where theoretically the number of social interactions is higher. A 399 relevant number of the red-coloured polygons corresponds to residential land uses, where the 400 virus spreads mostly in familiar environments. The dichotomy between centre and periphery is 401 more or less evident depending on the zoom view. Ten census districts in this municipality did not 402 report any COVID-19 case, paradoxically some of these districts located close to the downtown. 403 A more detailed view of the spatial distribution of cases in this city is visible in the following figures, 
404 where we can compare two ways for mapping the spatial distribution of the virus: aggregated 405 representation of the cases by census districts (Figure 6.2.b) or disaggregated representation of 406 the cases in dots (Figure 6.2.c).

407

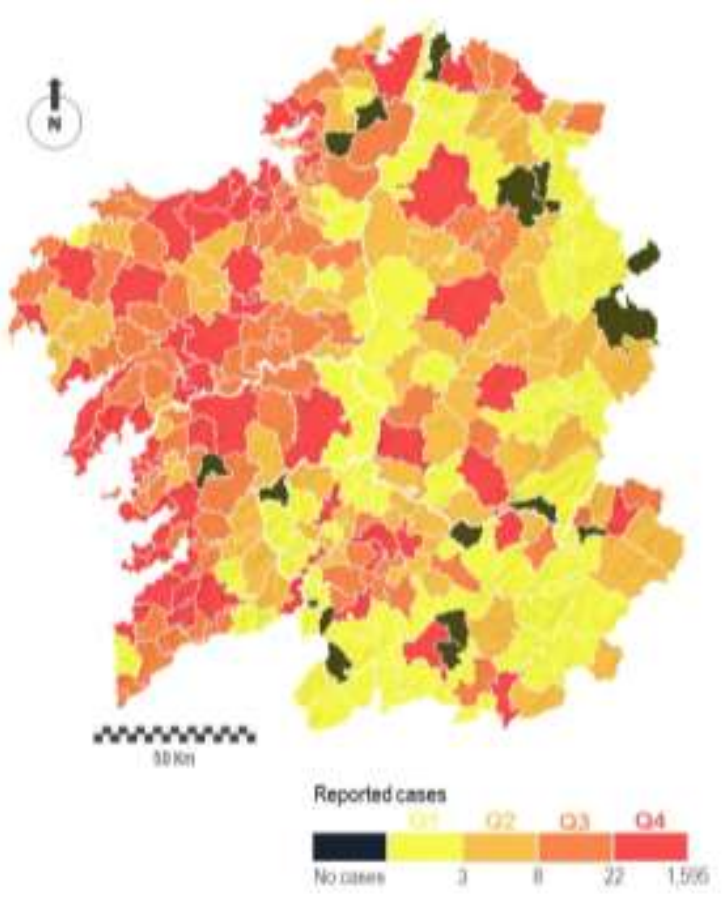

(a)

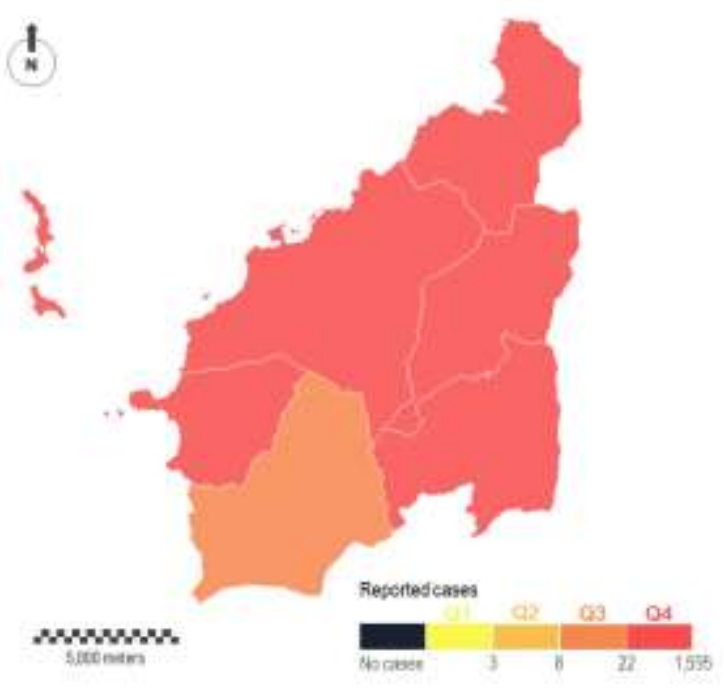

(b)

Figure 6.1. Number of CoVID-19 cases officially reported at a local scale of aggregation 409 (municipalities). (a) Mapping data for the whole region. (b) Mapping data for a small case study 410 located in the region of Vigo. Value intervals are distributed in regular quartiles. 


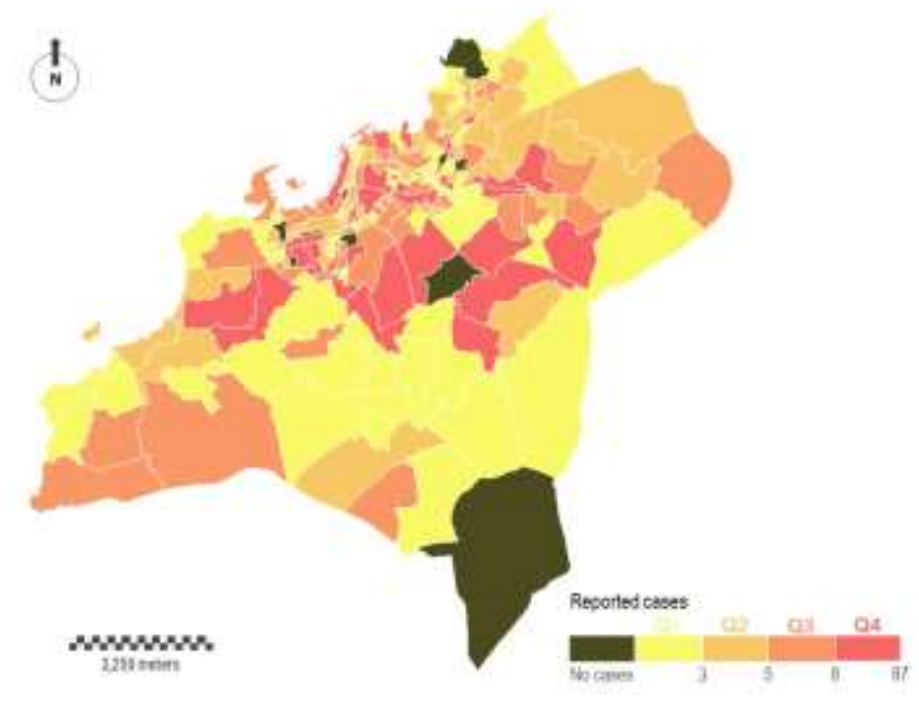

(a)

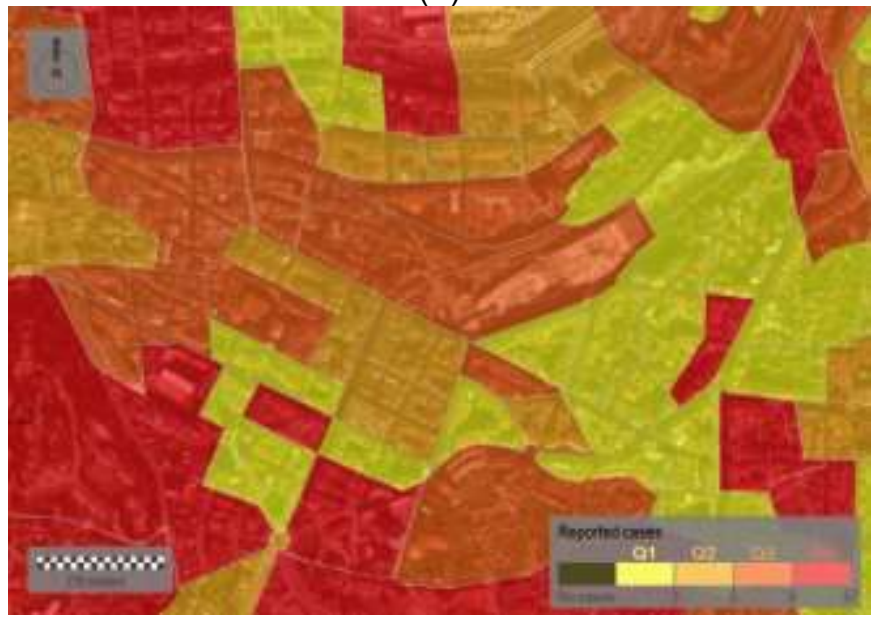

(b)

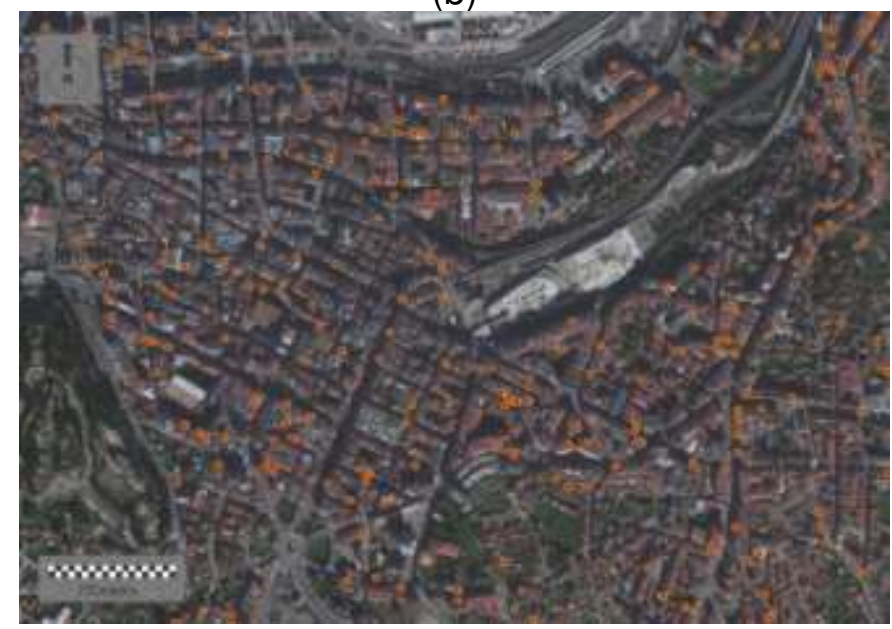

(c)

Figure 6.2. (a) Number of COVID-19 cases officially reported at an intermediate scale of aggregation (census districts) in the municipality of Vigo. Value intervals are distributed in representation of reported cases in the same area. 
417 A problem of choropleth maps is that the values subscribe to specific areas, showing sharp 418 boundaries between polygons. This can generate a biased visual perception of the represented 419 phenomenon [65]. Risk delimitation per area may arbitrarily change depending on both the level 420 of data aggregation and the geometric entity used for mapping. Figure 7 represents the density 421 of COVID-19 cases in a specific area of A Coruña, the second most populated city in this region 422 with about 250,000 inhabitants (study area B in Figure 2.b). The sample area represented is 423 located to the south and covers an area of 0.21 square kilometres (Figure 7.a). The urban 424 physiognomy of this area is structured from a dense street network. It is dominated by buildings 425 of about five floors high. Although the layout of the streets is mostly rectilinear, the urban fabric is 426 irregular and lacking in orthogonality. In addition, there is a general lack of green spaces. The 427 COVID-19 cases are aggregately represented in street sections. In this way, we establish a 428 zoning of the public space according to the risk levels. Two short street sections, symbolised in 429 red and in a wider line, are those that concentrate more cases. In 91 of 130 street sections, 430 symbolised in white and with a lower thickness, no cases were registered.

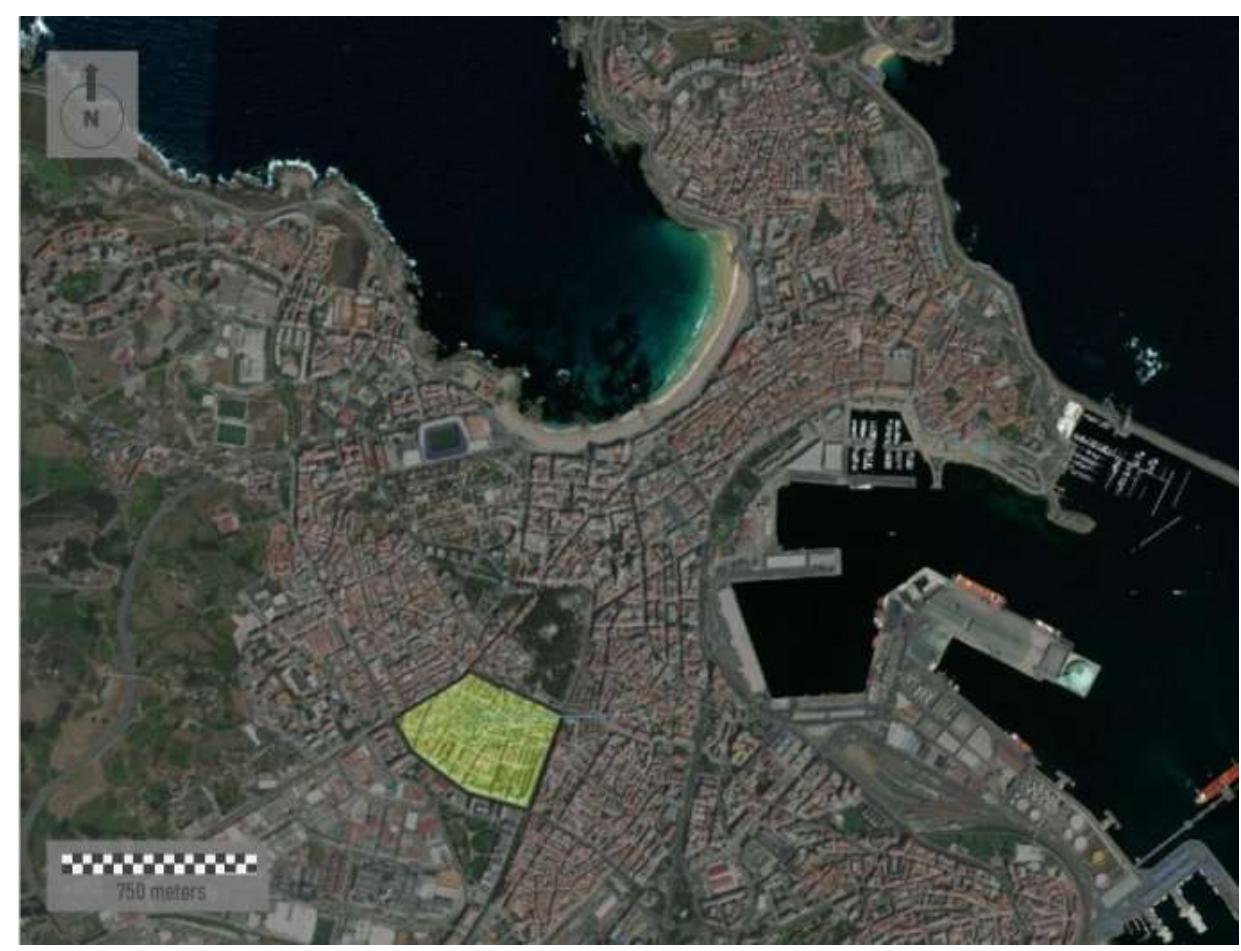


(a)

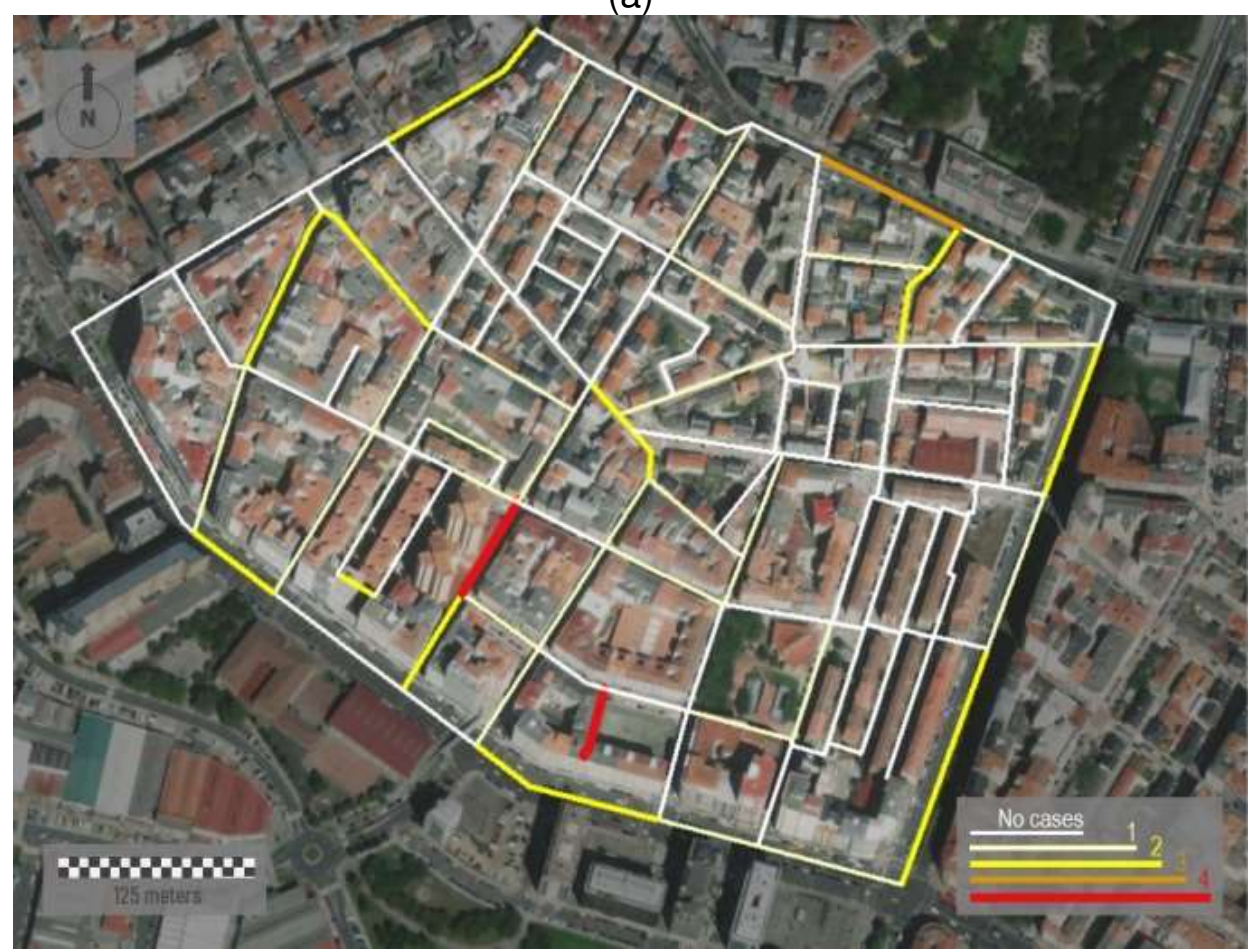

(b)

432
Figure 7. Number of COVID-19 cases officially reported in a specific area of $A$ Coruña. (a) In yellow, we represent the location of this sample area within the city. (b) Data mapping of reported cases at the lowest scale of aggregation (street sections).

The disaggregated representation of the data in single nodes allows to achieve the maximum level of detail and spatial resolution. However, this sort of representation has certain disadvantages, especially when we manage sensitive data due to privacy concerns. Figure 8 represents three sample areas with different territorial typologies: urban, semi-urban, and rural. The first sub-image, Figure 8.a, represents a random sample area located in downtown of Santiago de Compostela, the capital of the region (study area C in Figure 2.b). This part of the city presents an urban structure of open blocks with large patios. It is comprised of narrow streets with a rectilinear layout and tall buildings, over five floors high. Figure $8 . b$ is corresponds to the centre of a middle town. Santa Comba (study area D in Figure 2.b). This town has about 3,000 inhabitants, but it is the most important urban referent for its municipality, with a population of about 10,000 inhabitants. The urban planning of this nucleus is characterised by an orthogonal 
448 layout and a dense use of urban space, with buildings of variable height, from one to six floors 449 high [64]. Finally, Figure 8.c corresponds to a distinctly rural area located somewhere in the north 450 of the region. This small village has a concentrated physiognomy of a few mainly ground-floor 451 houses. Disaggregated mapping of COVID-19 cases by representing the personal addresses in 452 form of dots must be never carried out in eminently rural environments nor, in many cases, in 453 semi-urban ones since it is not clear whether the anonymity and privacy of those affected can be 454 guaranteed. Therefore, it is necessary to propose effective and responsible mapping strategies 455 adapted to each zoom factor and spatial scale.

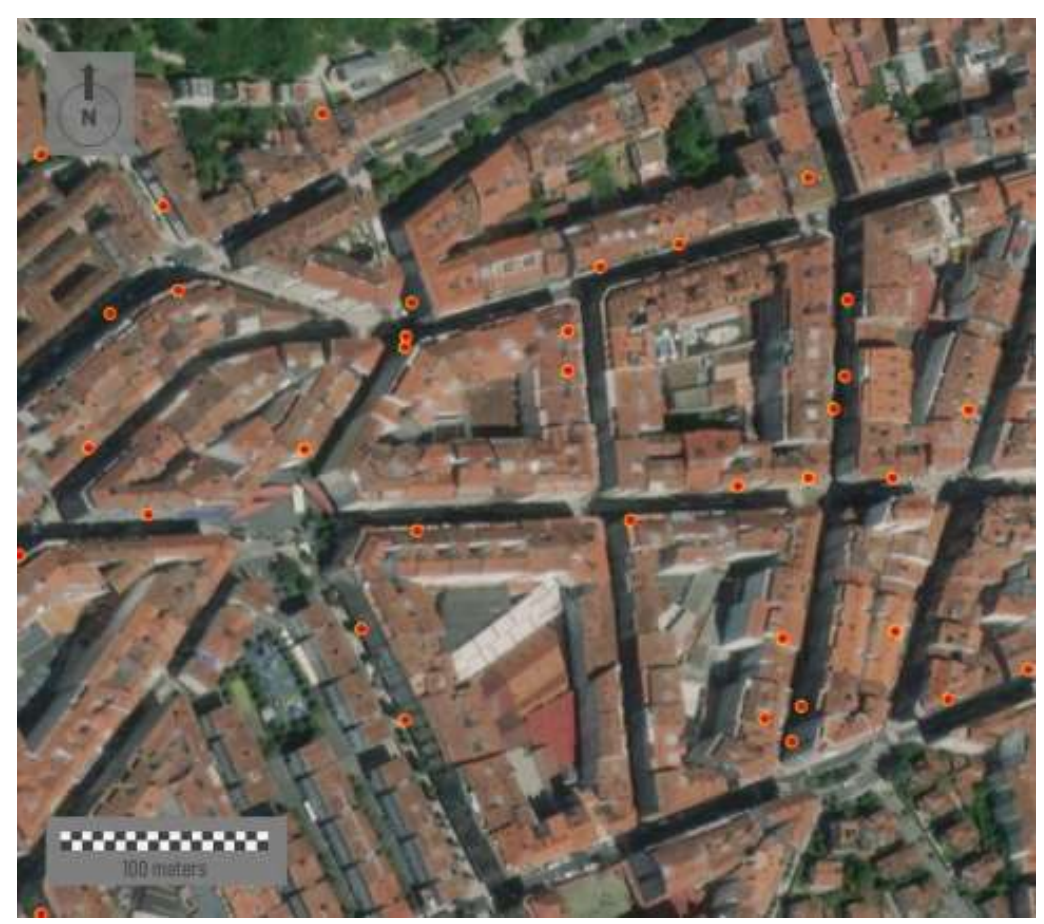

(a) 


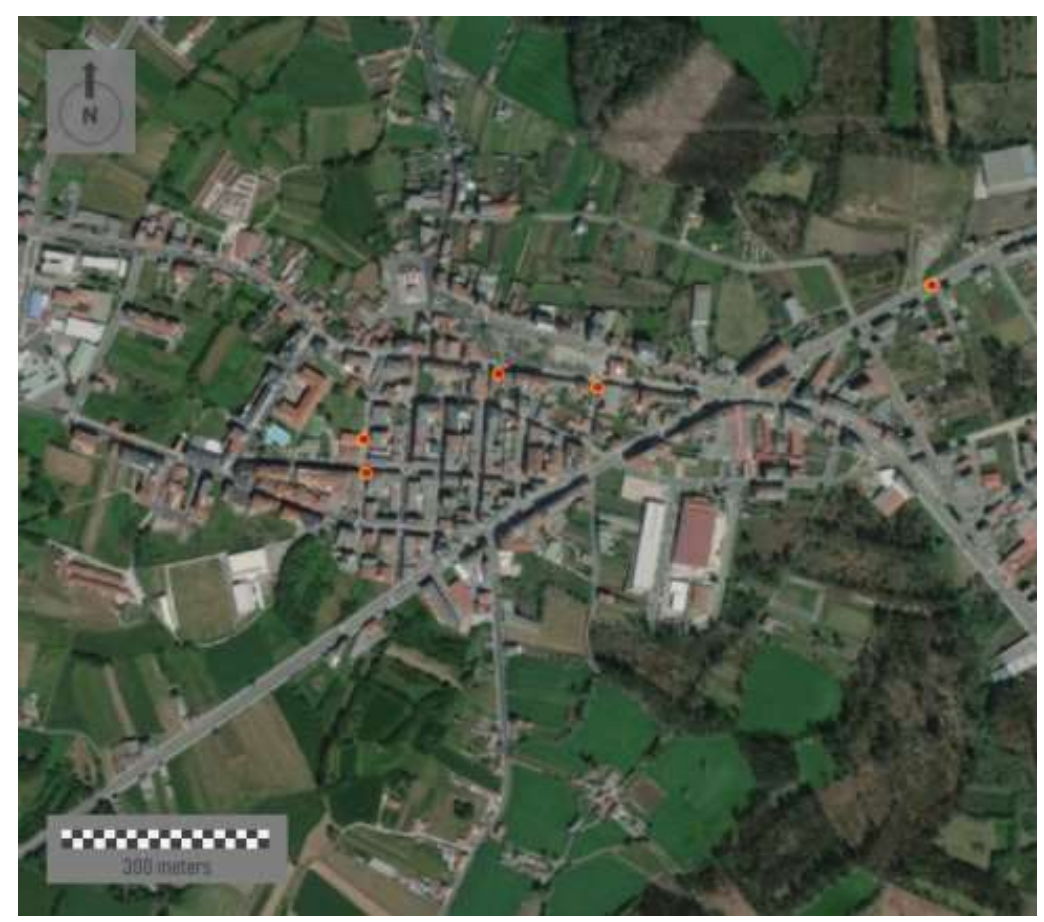

(b)

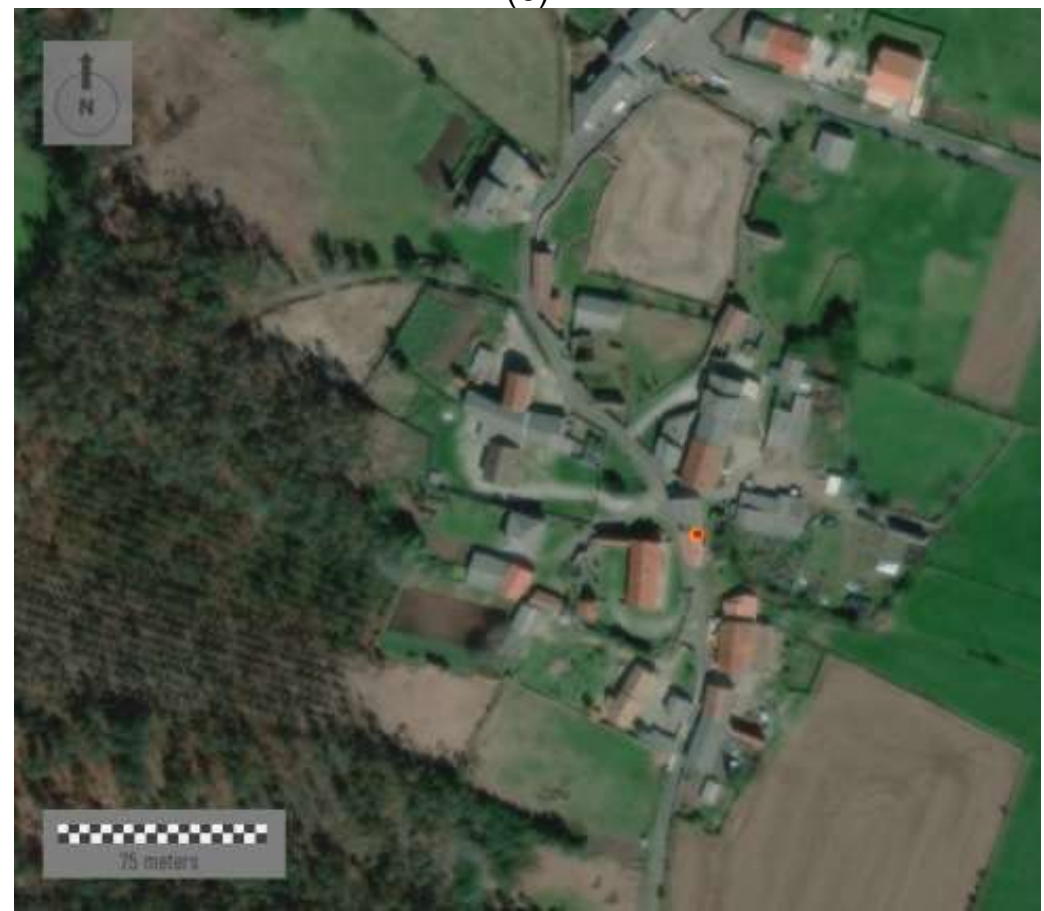

(c)

Figure 8. Location of COVID-19 cases in different sample areas: (a) A specific area in the downtown of the city of Santiago de Compostela, (b) the centre of a head town located in the 
461 The disaggregated representation of COVID-19 cases in dots may confuse the identification and 462 extraction of spatial patterns at some spatio-temporal scales. The following figures show the 463 temporal evolution of COVID-19 cases in Ourense's downtown, the third most populated city with 464 about 105,000 inhabitants (study area E in Figure 2.b). Figure 9.a represents the cases reported 465 on $15^{\text {th }}$ April, while Figure $9 . b$ is for $15^{\text {th }}$ July. The first sub-figure represents a total of 254 points 466 and the second one 546 points, which is more than double. Even though it is a substantial 467 difference, it results difficult to identify incidence patterns. Figures 9.c and 9.d represent the same 468 data in a raster map where it is represented the cases density. These maps show a more clear 469 view of the infection risks in this area by considering the time evolution. It is also convenient to 470 use an aerial image as background, which allow us to clearly identify of the spatial patterns and 471 to propose hypothesis about the potential sources of infection.

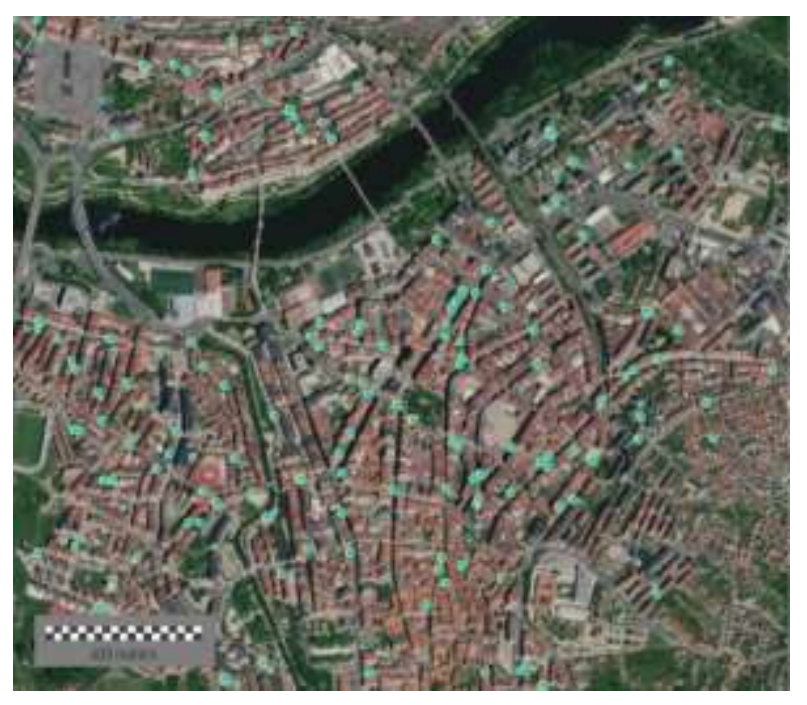

(a)

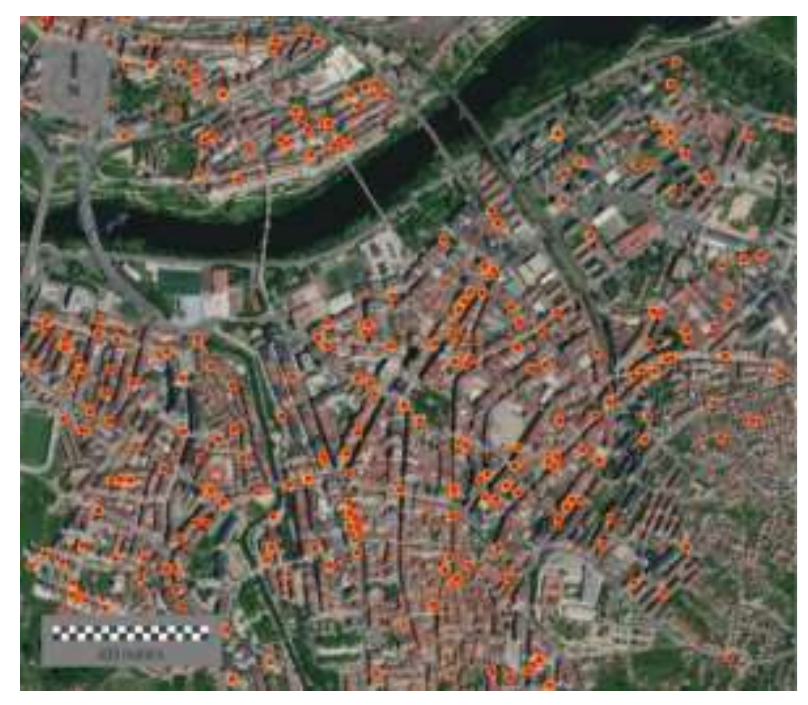

(b) 


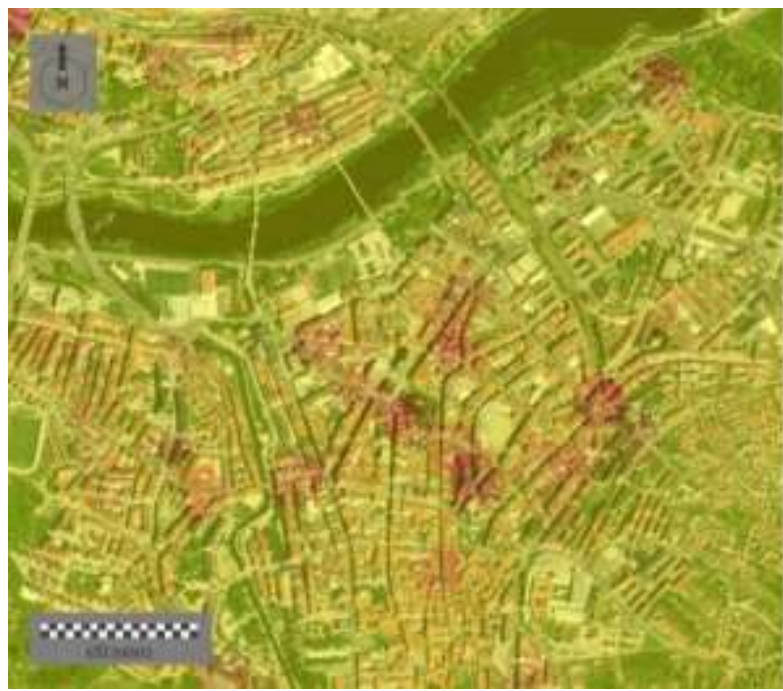

(c)

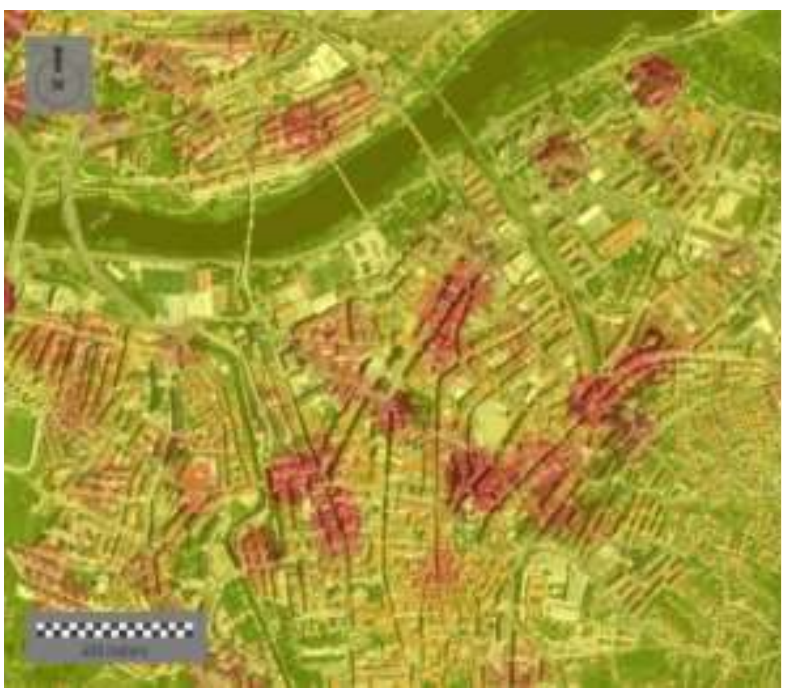

(d)

472 Figure 9. Temporal evolution of COVID-19 cases within the city of Ourense. (a) Disaggregated 473 mapping of cases (a) on $1^{\text {st }}$ April and (b) on $15^{\text {th }}$ July. Heat map based on cases density for the above dates: (c) $1^{\text {st }}$ April and (d) $15^{\text {th }}$ July. The areas with the highest concentration of dots correspond to the areas in red. Raster composed of 272 columns and 356 rows, with a cell size $10 \times 10$.

479 area, that is, the public space. Figure 10.a corresponds to a sample area located in the downtown 480 of the same city. This area presents a medium-high urban density, with different types of city 481 blocks and a limited presence of green spaces. The layout of the streets, although mostly 482 rectilinear, is characterised by its lack of orthogonality. Figure 10.b shows the accumulated 483 incidence of COVID-19 cases as of $15^{\text {th }}$ July. Overlapping this figure, we locate and represent a 484 series of socio-community centres and public facilities, such as educational centres, hospitals, 485 pharmacies, and health centres. The simultaneous mapping of both factors allow us to evaluate 486 the spatial correlation only considering the public space. Among other relevant aspects, we can 487 identify some outbreaks near educational centres. 


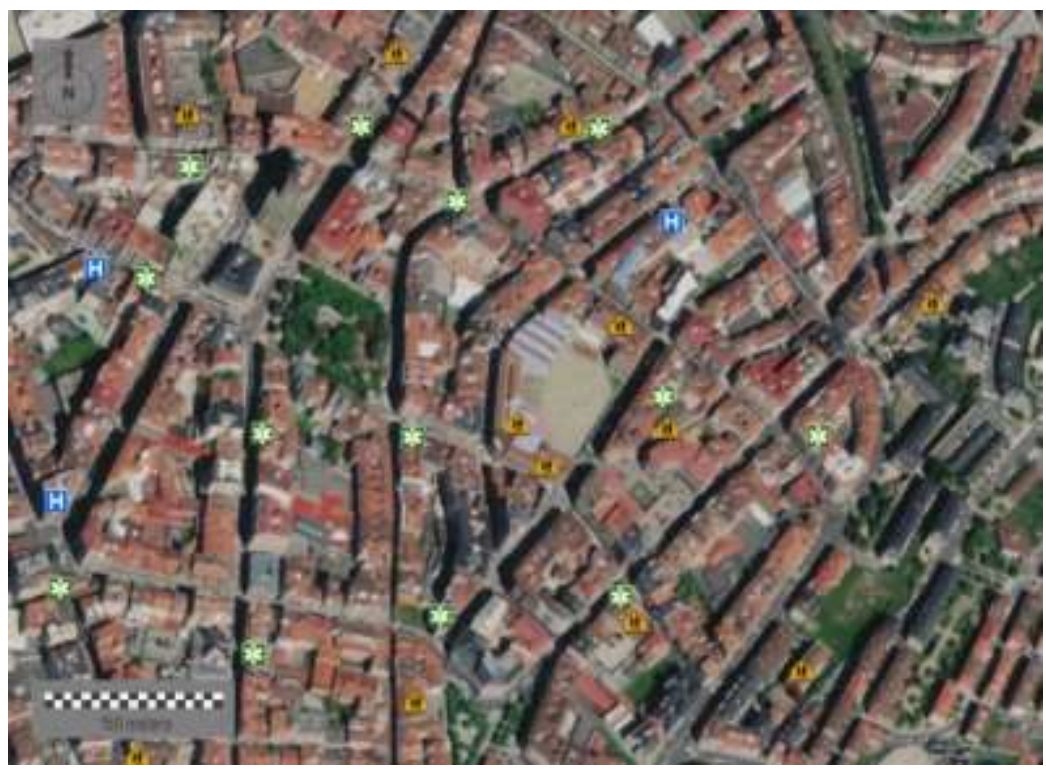

(a)

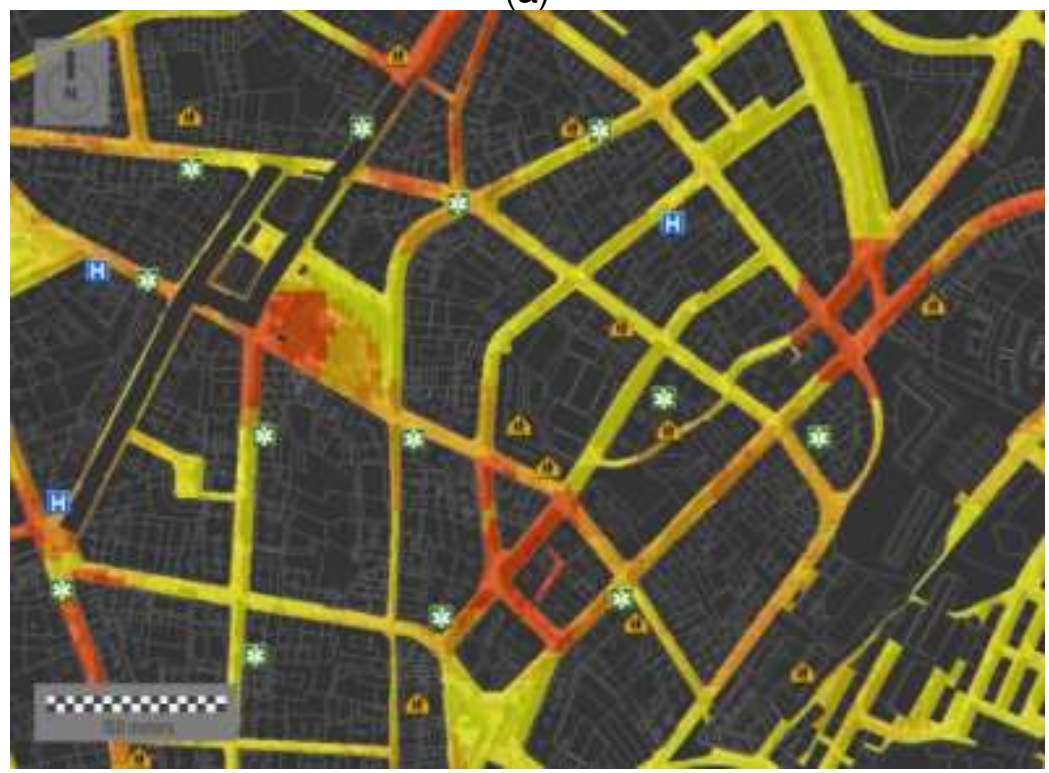

(b)

488 Figure 10. Analysis of the incidence of COVID-19 in a sample area of Ourense's downtown. (a) $489 \quad$ Aerial image of this sample area. (b) Mapping those areas with the highest concentration of 490 cases within the public space, i.e. streets and parks. The rest of the urban space is represented $491 \quad$ with a grey dark colour. To add further value to these maps, we overlap a series of public 492 facilities (such as educational centres, pharmacies, health centres) that potentially influence the 493 spread of the virus. Raster composed of 272 columns and 356 rows, with a cell size $10 \times 10$.

\section{Interpretation of the Results and Discussion}

497 The COVID-19 pandemic has violently hit the world, generating a great uncertainty from the 498 social, health, and economic perspectives. The situation of exceptionality and anguish 
experienced with COVID-19 has forced the administrations and health authorities to propose

500 unusual strategies in search of joining forces and finding answers. Some of them have understood

501 the challenge and decided to share fine-grained and sensitive data with the scientific community.

502 These data have made it possible to conduct complex analyses at all the spatial scales, allowing

503 to achieve a better understanding of the spread of the virus.

504 Maps are fundamental tools that contribute to find solutions for emergencies such as those

505 caused by COVID-19. Basically, geospatial analysis tools are capable to simplify complex, often

506 abstract, realities turning them into graphical translations through arbitrary symbols. Given the

507 emergence of COVID-19, geospatial analysis tools allow to simultaneously study all the

508 environmental risk factors that may influence the virus spreading.

509 Spatial analysts must respond to what issue to represent, how and for what purpose. The first 510 point determines the type and amount of information to be displayed. The second point 511 determines aspects related to the symbology or the organisation of the information, among others.

512 The last point determines the final objective of the map. Although there are a series of good 513 practices in how a map should be configured, its result must be adapted to the final message it 514 intends to convey and the audience to which it is transmitted [66]. The message must be clear, 515 unambiguous, and self-explanatory. A clear representation of this message facilitates the 516 subsequent steps related to the analysis and interpretation of the data.

517 During the pandemic, numerous institutions and governments have implemented web 518 dashboards for visualizing COVID-19 data using GIS tools. Although most are informative to raise 519 awareness, these sort of maps may be used as decision-making tools. However, it has some 520 requirements related to updated, detailed and spatial disaggregated datasets, in addition to the 521 need to implement appropriate mapping strategies for each particular objective. GIS tools allow 522 to synthesize the complex abstraction of reality in data layers, which can be managed, organized, 523 overlapped, and customized according to the requirements of the operator [67]. Beyond the value 524 of these geospatial tools, the cartographic treatment of data by some of these web dashboards 
525 has been widely criticised. In fact, it is frequent an excess of tools that take a long time to load 526 and do not work correctly, the predominance of complex and counter-intuitive designs, and/or 527 some platforms with limited effectiveness. The same happens with the design of the maps, with 528 a tendency to over- or under- represent information, in addition to inappropriate uses of choropleth 529 maps and different cartographic features such as datum, projection systems, and scales [68].

530 Here we present some mapping strategies using fine-grained and detailed COVID-19 data. For 531 this purpose, we show different solutions in form of maps. Data are plotted using simple features 532 (points, lines, and polygons), whose use depends on fundamental aspects such as the 533 representation scale or the level of aggregation of the data. However, both aspects must be 534 adjusted according to the privacy and sensitivity of the data. Health data mapping must pursue 535 their objectives while preserving aspects such as the data integrity, user privacy, self-sovereign 536 data ownership, as well as the compliance of the legislation on data protection. In consequence, 537 it requires implementing strategies and approaches to data governance for ensuring that data are 538 appropriately managed [69].

539 There is a complex trade-off between transparency to provide the more reliable information to 540 society and to avoid the shortcomings derived from it. In the case of the pandemic, a very detailed 541 representation of COVID-19 cases can be counterproductive creating an unjustified state of 542 general alarm or leading to a rejection of certain individuals or communities. It is also applied to 543 mapping strategies, being required to adopt certain arbitrary criteria (quantitative or visual) for 544 preserving the anonymity of users. Just for example, an infected individual that is represented by 545 a single dot may not be easily identified in an urban environment, but it can indeed be in a more 546 rural environment. In the particular case of the region of Galicia, this is even more complicated in 547 areas with an apparently urban physiognomy, such as in head towns, where data privacy cannot 548 be guaranteed when finest grained data are represented. It requires the need to know the territory 549 and to implement data aggregation strategies according with the particular characteristics of the 550 study area. 
551 Application of geospatial tools to the current pandemic is just one example more of the potential 552 of GIS tools in health data management [70]. In the last few years, volume of health datasets has 553 exponentially grown due to the enhanced capacity of portable devices like wearables, which have

554 favoured the explosion of personal health data [71]. It explains the progressive shift of data and 555 services to the cloud, partly due to convenience (availability of complete patient medical history 556 in real-time) and cost savings [72]. This paradigm is favouring the creation of multidisciplinary 557 work teams in order to reach more creative and efficient solutions to face a multifaceted issue 558 such as the health management. Precisely in this respect that maps are an essential tool for 559 integrating experts with different backgrounds in the same teamwork. An appropriate 560 representation of data facilitates a comprehensive interpretation of the spatio-temporal behaviour 561 of the virus from different analysis perspectives by increasing the interactions between experts.

562 The importance of GIS tools goes far beyond traditional map generation. These may be used as 563 centralized systems for managing data in (near)-real time. This represents a great benefit for 564 subsequent steps of the pandemic such as the digital tracing for reported cases, but also for 565 people at risk [70]. The success of interventions adopted by some countries is mostly based on 566 this sort of technologies, which is greatly minimizing the impact of the virus on health, social, and 567 economic terms.

568 Several aspects must be considered in our research. We use information from structured 569 datasets, which have been pre-processed before to their representation. However, future in health 570 management points more towards the representation unstructured datasets coming from 571 personal devices, home sensors, and wearables. It will require to advance in new strategies and 572 methodologies for handling, managing, and mapping these data. According to Fornace et al. [73], 573 efforts will be focused on developing real-time high-resolution mapping strategies ready to be 574 used with mobile technology-based applications.

575 Our proposal must be framed in a very exceptional context related with the COVID-19 crisis, which 576 had encouraged many public administrations to share information. However, this experience must 
577 go beyond. Nowadays, many governments are trying to implement open data platforms where

578 data are available in non-proprietary formats, free of charges, and without distribution rights [74].

579 This, together with the ongoing digital transformation process in health management, requires the

580 implementation of strategies that allow facing new challenges to improve population health, to

581 enhance the quality of care services, and to reduce cost growths (i.e., the so-called triple aim)

$582[75]$.

583 Finally, maps presented here serve to extract actual spatial patterns within a geographical 584 context. In this way, we can evaluate the natural spreading of the virus in this region, but also the 585 effectiveness of the interventions adopted to deal with it. A general reading of the figures show 586 how this region was one of the least severely affected by COVID-19 in the first wave. This is 587 largely due to the adoption of the harsh lockdown at a national level when the pandemic was still

588 in an initial phase in this region. The spread of the virus presents a spatial pattern very similar to 589 the regional structure of human settlements. Most of the reported cases were concentrated in the 590 most populated areas, close to the Atlantic Axis. In future studies, the authors will conduct a more 591 comprehensive analysis of these spatial patterns in this region at multiple scales.

593 Conclusions

594 Geospatial tools are playing a very relevant role throughout the current COVID-19 pandemic. 595 Dashboards, web-based tools, and traditional maps allow sharing information with dwellers, 596 whereas governments and authorities gain transparency for their public management. However, 597 the importance of these tools must be further than merely informative, becoming an essential tool 598 for decision-making in almost real time.

599 It requires a willingness to share fine-grained, detailed, and accurate information by responsible 600 authorities. However, there are some concerns related to mapping these data to be considered. 601 Among them, to keep the privacy of people or to avoid counterproductive effects such as 
602 generating unjustified false alarms in the population. Geospatial data plays a key role in any 603 visualization strategy. For this purpose, an appropriate and responsible management of geodata 604 is required, adapting the maps to specific audiences and purposes. In addition to an optimal use 605 of all the map's elements, the cartographer must implement the most appropriate strategies for 606 mapping according to the particular objectives at any time.

607 In this article, we present some strategies for mapping fine-grained and detailed COVID-19 data.

608 These data are geoprocessed with GIS tools and final maps are adapted to different objectives 609 and scales. Our objective is to enhance the value of these data for making decision. Data 610 visualization must be clear and adapted to the audience, by facilitating the integration of 611 epidemiologists, health authorities, and policymakers to adopt the best decisions at multiple 612 scales.

614 Availability of data and materials

615 Aggregated data are partially published by the National Centre of Epidemiology (Health Institute 616 Carlos III, Spain) and the Galician Health Service (SERGAS). Fine-grained data were yielded to 617 the authors under confidentiality.

\section{References}

620 [1] Ortega A. Coronavirus: trends and landscapes for the aftermath. Elcano Royal Institute: ARI 51/2020. 6212020.

622 http://www.realinstitutoelcano.org/wps/portal/rielcano_en/contenido?WCM_GLOBAL_CONTEXT=/elcano/ 623 elcano_in/zonas_in/ari-51-2020-ortega-coronavirus-trends-and-landscapes-for-the-aftermath. Accessed 62415 Feb 2021.

625 [2] Chakraborty I, Maity P. COVID-19 outbreak: Migration, effects on society, global environment and 626 prevention. Sci Total Environ. 2020; doi: 10.1016/j.scitotenv.2020.138882.

627 [3] Bambra C, Riordan R, Ford J, Matthews F. The COVID-19 pandemic and health inequalities. J Epidemiol 628 Community Health. 2020;74:964-968.

629 [4] Cicalò E, Valentino F. Mapping and visualisation of health data. The contribution of the graphic sciences 630 to medical research from New York yellow fever to China coronavirus. Disegnarecon 2019;12(23):12-21.

631 [5] COVID-19 Dashboard by the Center for Systems Science and Engineering at Johns Hopkins University. 632 https://coronavirus.jhu.edu/map.html. Accessed 15 Feb 2021.

633 [6] World Health Organization coronavirus disease (COVID-19) dashboard. https://covid19.who.int. 634 Accessed 15 Feb 2021. 
[7] Heathmap. Novel coronavirus 2019-nCOV dashboard. https://healthmap.org/wuhan. Accessed $15 \mathrm{Feb}$ 2021.

[8] Boulos MN, Geraghty EM. Geographical tracking and mapping of coronavirus disease COVID-19/severe acute respiratory syndrome coronavirus 2 (SARS-CoV-2) epidemic and associated events around the world: how 21st century GIS technologies are supporting the global fight against outbreaks and epidemics. Int J Health Geogr. 2020;19(1):8.

641 [9] Skorup B, Haaland C. How drones can help fight the coronavirus. Mercatus Center Research Paper 642 Series. 2020; doi:10.2139/ssrn.3564671.

643 [10] Balsa-Barreiro J, Lerma JL. Aplicación de la tecnología del láser escáner aerotransportado (ALS) a la generación de modelos digitales urbanos. Topografía y Cartografía. 2006; 23(136):3-8.

645 [11] China launches coronavirus 'close contact detector' app. BBC. 2020. https://www.bbc.com/news/technology-51439401. Accessed 15 Feb 2021.

6482021.

649 [13] Nakamoto I, Jiang M, Zhang J, Zhuang W, Guo Y, Jin M, Huang Y, Tang K. Evaluation of the design 650 and implementation of a peer-to-peer COVID-19 contact tracing mobile app (COCOA) in Japan. 651 2020;8(12);e22098; doi:10.2196/22098.

652 [14] Federal Office of Public Health. Coronavirus: SwissCovid app and contact tracing. 2020. 653 https://www.bag.admin.ch/bag/en/home/krankheiten/ausbrueche-epidemien-pandemien/aktuelle-

654 ausbrueche-epidemien/novel-cov/swisscovid-app-und-contact-tracing.html. Accessed 15 Feb 2021.

655 [15] Gobierno de España. RadarCovid. 2020. https://radarcovid.gob.es. Accessed 15 Feb 2021.

656 [16] Gardner L. Update January 31: modelling the spreading risk of 2019-nCoV. Center for Systems 657 Science and Engineering, Johns Hopkins Whiting School of Engineering. 2020. 658 https://systems.jhu.edu/research/public-health/ncov-model-2. Accessed 15 Feb 2021.

[17] Yu WB, Tang GD, Zhang L, Corlett RT. Decoding the evolution and transmissions of the novel

662 [18] Goldsmith S, Leger MA. Shining moment for GIS: responding to COVID-19 with maps. Harvard

663 Kennedy School, ASH Center for Democratic Governance and Innovation. 2020. $664 \mathrm{https}: / /$ datasmart.ash.harvard.edu/news/article/shining-moment-gis-responding-covid-19-maps. Accessed $66515 \mathrm{Feb} 2021$.

666 [19] García-Basteiro A et al. The need for an independent evaluation of the COVID-19 response in Spain. 667 Lancet. 2020; 396(10250): 529-530.

668 [20] Trias-Llimós S, Alustiza A, Prats C, Tobias A, Rif T. The need for detailed COVID-19 data in Spain. 669 Lancet Public Health. 2020;5(11):e576; doi:10.1016/S2468-2667(20)30234-6.

670 [21] The Lancet Public Health Editorial. COVID-19 in Spain: a predictable storm? Lancet Public Health. 671 2020;5(11):e568; doi:10.1016/S2468-2667(20)30239-5.

672 [22] Gross B, Zheng Z, Liu S, Chen X, Sela A, Li J, Li D, Havlin S. Spatio-temporal propagation of COVID67319 pandemics. MedRxiv. 2020; doi: 10.1101/2020.03.23.20041517.

674 [23] Schnaiberg A, Gould K. Environment and society: the enduring conflict. Contemp Sociol. 1994;23(4); 675 doi: $10.2307 / 2076357$.

676 [24] Kearns R, Moon G. From medical to health geography: novelty, place and theory after a decade of 677 change. Prog Hum Geogr. 2002;26(5):605-625.

678 [25] Li J, Llu B, Li G, Chen Z, Sun X, Rong S. Atlas of cancer mortality in the People's Republic of China. 679 An aid for cancer control and research. Int J Epidemiol. 1981;10(2):127-133. 
[26] Devesa S, Grauman DJ, Blot WJ, Pennello, GA, Hoover RN. Atlas of cancer mortality in the United States, 1950-94. Michigan: National Institutes of Health, National Cancer Institute; 1999.

682 [27] Kulldorff M, Song C., Gregorio D, Samociuk H, DeChello L. Cancer map patterns: are they random or not? Am J Preventive Med. 2006;30(2):S37-S49.

684 [28] Castronovo DA, Chui KK, Naumova EN. Dynamic maps: a visual-analytic methodology for exploring spatio-temporal disease patterns. Environmental Health. 2009;8:61.

686 [29] Mohd K, Jacobsen KH, Wiersma ST. Challenges to mapping the health risk of hepatitis A virus infection. Int J Health Geogr. 2011;10:57; doi:10.1186/1476-072X-10-57.

[30] Koch T. Plague: Bari, Naples 1690-1692. In: Koch T, editor. Cartographies of disease: maps, mapping and medicine. Redlands: Esri Press; 2005. p. 19-24.

[31] Shiode N, Shiode S, Rod-Thatcher E, et al. The mortality rates and the space-time patterns of John Snow's cholera epidemic map. Int J Health Geogr. 2015;14:21; doi:10.1186/s12942-015-0011-y.

692 [32] Lyseen AK, Nøhr C, Sørensen EM, Gudes O, Geraghty EM, Shaw NT, Bivona-Tellez C. A review and framework for categorizing current research and development in health related geographical information

[33] Wahid B, Ali A, Rafique S, Idrees M. Global expansion of chikungunya virus: mapping the 64-year history. Int J Infect Dis. 2017;58:69-76.

[34] Pigott DM, Golding N, Mylne A, Huang Z, Henry AJ, Weiss DJ, Brady OJ, Kraemer MU, Smith DL, Moyes CL, Bhatt S, Gething PW, Horby PW, Bogoch II, Brownstein JS, Mekaru SR, Tatem AJ, Khan K, Hay SI. Mapping the zoonotic niche of Ebola virus disease in Africa. Elife. 2014;8(3):e04395; doi: 10.7554/eLife.04395.

[35] Cattarino, L., Rodriguez-Barraquer, I., Imai, N., Cummings, D.A.T., Ferguson, N.m. Mapping global variation in dengue transmission intensity. Sci TransI Med. 2020; doi: 10.1126/scitransImed.aax4144.

[36] Samy AM, Thomas SM, Wahed A, C KP, Peterson A. Mapping the global geographic potential of Zika virus spread. Memórias do Instituto Oswaldo Cruz. 2016; 111(9):559-560.

[37] Messina JP, Kraemer MU, Brady OJ, Pigott DM, Shearer FM, Weiss DJ, Golding N, Ruktanonchai CW, Gething PW, Cohn E, Brownstein JS, Khan K, Tatem AJ, Jaenisch T, Murray CJ, Marinho F, Scott TW, Hay SI. Mapping global environmental suitability for Zika virus. Elife. 2016;19(5):e15272; doi:10.7554/eLife.15272.

[38] Reeves T, Samy AM, Peterson AT. MERS-CoV geography and ecology in the Middle East: analyses of reported camel exposures and a preliminary risk map. BMC Res Notes. 2015;8:801; doi:10.1186/s13104015-1789-1.

[39] Deka MA, Morshed N. Mapping disease transmission risk of Nipah virus in south and southeast Asia. Trop Med Infect Dis. 2018; 3(2):57.

[40] Sánchez-Gómez A, Amela C, Fernández-Carrión E, Martínez-Avilés M, Sánchez-Vizcaíno JM, SierraMoros MJ. Risk mapping of West Nile virus circulation in Spain. Acta Trop. 2017; 169:163-169.

[41] Xiong C, Hu S, Yang M, Luo W, Zhang L. Mobile device data reveal the dynamics in a positive relationship between human mobility and COVID-19 infections. PNAS. 2020;117(44): 27087-89.

[42] Richardson DB, Volkow ND, Kwan MP, Kaplan RM, Goodchild MF, Croyle RT. Medicine. Spatial turn in health research. Science. 2013;339(6126):1390-2.

[43] Grantz KH, Rane MS, Salje H, Glass GE, Schachterle SE, Cummings D. Sociodemographic disparities of influenza in 1918. PNAS. 2016;113 (48):13839-44.

[44] Allcott H, Boxell L, Conway J, Gentzkow M, Thaler M, Yang D. Polarization and public health: partisan differences in social distancing during the coronavirus pandemic. NBER Working Paper No. w26946. 2020. 
[45] Parks D, MacDonald N, Beiko R. Tracking the evolution and geographic spread of Influenza A. PLOS Currents Influenza. 2009; doi: 10.1371/currents.RRN1014.

[46] Gikonyo S, Kimani T, Matere J. et al. Mapping potential amplification and transmission hotspots for MERS-CoV, Kenya. EcoHealth. 2018;15:372-387.

728 [47] Fuller TL, Saatchi SS, Curd EE et al. Mapping the risk of avian influenza in wild birds in the US. BMC Infect Dis. 2010; doi:10.1186/1471-2334-10-187.

[48] Zhou P, Yang XL, Wang XG et al. A pneumonia outbreak associated with a new coronavirus of probable bat origin. Nature. 2020;579:270-3.

[49] Amdaoud M, Arcuri G, Levratto N, Succurro M, Costanzo D. Geography of COVID-19 outbreak and first policy answers in European regions and cities. Archive ouverte en Sciences de l'Homme et de la Société. 2020. https://halshs.archives-ouvertes.fr/halshs-03046489. Accessed 15 Feb 2021.

[50] Alain-Dupré D. et al. The territorial impact of COVID-19: managing the crisis across levels of government. OECD Policy Responses to Coronavirus. 2020. http://www.oecd.org/coronavirus/policyresponses/the-territorial-impact-of-covid-19-managing-the-crisis-across-levels-of-government-d3e314e1/. Accessed 15 Feb 2021.

[51] Ali N, Islam F. The effects of air pollution on COVID-19 infection and mortality. A review on recent evidence. Front. Public Health. 2020; doi:10.3389/fpubh.2020.580057.

[52] Oto-Peralías D. Regional correlations of COVID-19 in Spain. OSF preprints. 2020; doi:10.31219/osf.io/tjdgw.

[53] Wang F. Why public health needs GIS: a methodological overview. Ann GIS. 2020;26(1):1-12.

[54] Tuckel P et al. The diffusion of the influenza pandemic of 1918 in Hartford, Connecticut. Social Sci Hist. 2006; 30(2):167-196.

[55] Smallman-Raynor M, Johnson N, Cliff AD. The spatial anatomy of an epidemic: influenza in London and the county boroughs of England and Wales, 1918-1919. Trans Inst Br Geogr. 2002; 27: 452-470.

[56] Rodriguez-Morales AJ, Galindo-Marquez ML, García-Loaiza CJ et al. Mapping Zika virus disease incidence in Valle del Cauca. Infect. 2017;45:93-102.

[57] National Centre of Epidemiology, Health Institute Carlos III (Spain). 2020. https://cnecovid.isciii.es/covid19. Accessed 15 Feb 2021.

[58] Galician Covid Info. https://galiciancovid19.info. Accessed 15 Feb 2021.

[59] MoMo dashboard. Instituto de Salud Carlos III (Spain). https://momo.isciii.es/public/momo/dashboard/momo_dashboard.html. Accessed 15 Feb 2021.

[60] Romero JM. Los muertos de la pandemia en España: 44.868. El País. 2020. https://elpais.com/sociedad/2020-07-25/las-44868-muertes-de-la-pandemia-en-espana.html. Accessed $15 \mathrm{Feb} 2021$.

[61] Pollán, M. et al. Prevalence of SARS-CoV-2 in Spain (ENE-COVID): a nationwide, population-based seroepidemiological study. Lancet. 2020;396(10250):535-544.

[62] National Institute of Statistics. 2019. https://www.ine.es. Accessed 15 Feb 2021.

[63] Nomenclátor INE. Población del padrón continuo por unidad poblacional. 2020. https://www.ine.es/nomen2/index.do. Accessed 15 Feb 2021.

[64] Balsa-Barreiro J. Evolución del urbanismo y de la disposición territorial del poblamiento en un municipio coruñés de interior: el caso de Santa Comba (Galicia, España). Rev Urbanismo 2011;24:76-118.

[65] Azevedo L, Pereira MJ, Ribeiro MC, Soares A. Geostatistical COVID-19 infection risk maps for

767 [66] Robinson A, Sale R, Morrison J. Elements of cartography. New York: John Wiley and Sons; 1978. 
[67] Balsa-Barreiro J, Valero-Mora PM, Berné-Valero JL, Varela-García FA. GIS mapping of driving behavior based on naturalistic driving data. ISPRS Int J Geo-Inf. 2019;8:226. [68] Franch-Pardo I, Napoletano B, Rosete-Verges F, Billa L. Spatial analysis and GIS in the study of COVID-19. A review. Sci Total Environ. 2020; doi:10.1016/j.scitotenv.2020.140033.

[69] Brous P, Janssen M, Vilminko-Heikkinen R. Coordinating decision-making in data management activities: a systematic review of data governance principles. In Electronic Government EGOV 2016 International Conference Proc., Lecture Notes in Computer Science, Springer Verlag. 2016; 115-125.

[70] Rosenkrantz L, Schuurman N, Bell N, Amram O. The need for GIScience in mapping COVID-19. Health and Place. 2020; 67: 102389.

[71] Karampela M, Ouhbi S, Isomursu M. Personal health data: A systematic mapping study. Int J Med Inf. 2018;118:86-98.

[72] Esposito C, Santis A, Tortora G, Chang H, Kim-Kwang RC. Blockchain: a panacea for healthcare cloudbased data security and privacy? IEEE Cloud Comput. 2018; 5: 31-7.

[73] Fornace KM, Surendra H, Abidin TR, Reyes R, Macalinao MLM, Stresman G, Luchavez J, Ahmad RA, approaches to geolocate health facility attendees for disease surveillance in low resource settings. Int $J$ Health Geogr. 2018;17(1):21.

[74] Martin EG, Law J, Ran W, Helbig N, Birkhead GS. Evaluating the quality and usability of open data for public health research: a systematic review of data offerings on 3 open data platforms. J Public Health Manag Pract. 2017;23(4):e5-e13.

[75] Steenkamer BM, Drewes HW, Heijink R, Baan CA, Struijs JN. Defining population health management: a scoping review of the literature. Popul Health Manag. 2017;20(1):74-85.

\section{ACKNOWLEDGEMENTS}

792 The authors would like to thank the Galician Health Service (SERGAS), which depends on the 793 Xunta de Galicia (Spain), for providing the data used here.

\section{FUNDING}

796 This research project was funded by the Galician Innovation Agency.

\section{AUTHOR INFORMATION}

\section{Affiliations}

\section{Territorial Analysis research group, Galician Studies and Development} Institute (IDEGA), University of Santiago de Compostela, Avda. das 
Ángel Miramontes and José Balsa-Barreiro.

2. MIT Media Lab, Massachusetts Institute of Technology, 75 Amherst St., MA 02139, Cambridge, United States

806 José Balsa-Barreiro.

\section{Contributions}

809 Hereby we confirm that all listed authors have contributed to the study. AM was mostly 810 working on acquisition of data. JB was mostly focused on the analysis and interpretation

811 of results. JB and AM drafted the article.

\section{Authors' information}

814 Prof. Dr. Angel Miramontes (http://orcid.org/0000-0003-1162-3329) is Professor at the

815 Department of Geography and researcher at the Galician Studies and Development 816 Institute (IDEGA), University of Santiago de Compostela, Spain. Correspondence to

817 angel.miramontes@usc.es

818 Dr. José Balsa-Barreiro (http://orcid.org/0000-0001-7348-4198) is researcher at MIT

819 Media Lab, Massachusetts Institute of Technology, MIT, Cambridge (MA), United

820 States. He is also part of the Galician Studies and Development Institute (IDEGA),

821 University of Santiago de Compostela, Spain.

822

823 Corresponding author

824 Correspondence to angel.miramontes@usc.es 


\section{ETHICS DECLARATIONS}

\section{Ethics approval and consent to participate.}

828 Fine-grained data were yielded to the authors under confidentiality.

\section{Consent for publication}

830 Not applicable.

\section{Competing interests}

832 The authors declare that they have no competing interests. Not applicable.

\section{ADDITIONAL INFORMATION}

835 Publisher's Note

836 Springer Nature remains neutral with regard to jurisdictional claims in published maps and 837 institutional affiliations.

\section{RIGHTS AND PERMISSIONS}

840 Open Access This article is licensed under a Creative Commons Attribution 4.0 International

841 License, which permits use, sharing, adaptation, distribution and reproduction in any medium or

842 format, as long as you give appropriate credit to the original author(s) and the source, provide a 843 link to the Creative Commons licence, and indicate if changes were made. The images or other

844 third-party material in this article are included in the article's Creative Commons licence, unless

845 indicated otherwise in a credit line to the material. If material is not included in the article's Creative

846 Commons licence and your intended use is not permitted by statutory regulation or exceeds the 847 permitted use, you will need to obtain permission directly from the copyright holder. To view a 848 copy of this licence, visit http://creativecommons.org/licenses/by/4.0/. The Creative Commons 849 Public Domain Dedication waiver (http://creativecommons.org/publicdomain/zero/1.0/) applies to 850 the data made available in this article, unless otherwise stated in a credit line to the data. 


\section{Figures}

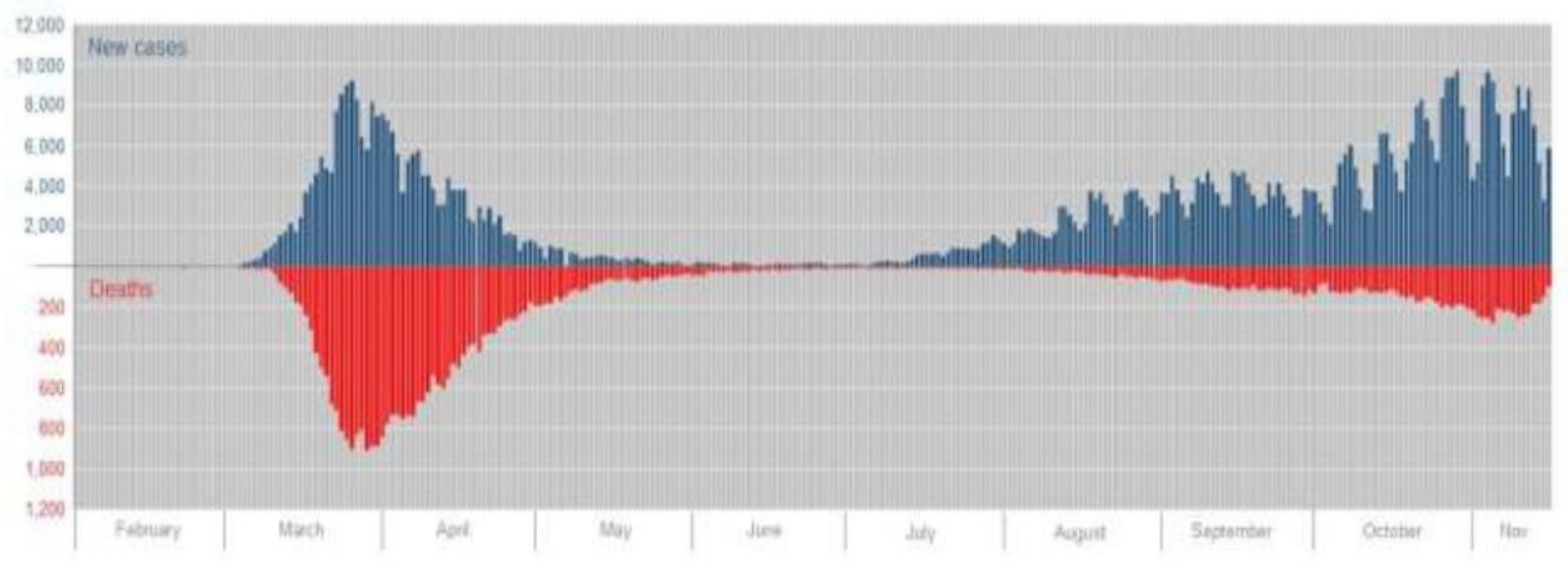

\section{Figure 1}

Number of reported cases and deaths from CoVID-19 in Spain since the beginning of the pandemic (31st January) until 15th November. Reported cases are shown in blue (Y-axis) and deaths in red (Y-axis inverted).

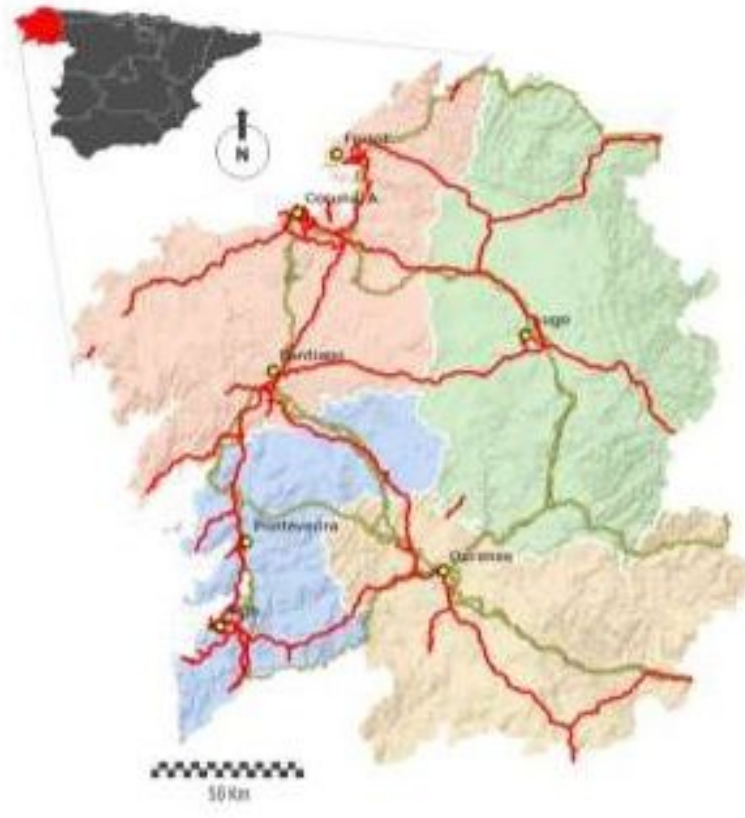

(a)

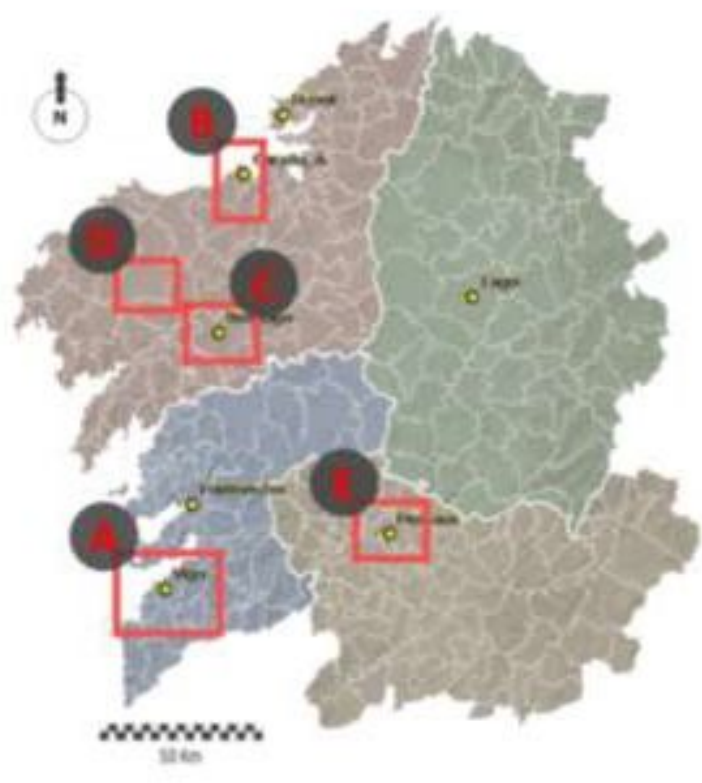

(b)

\section{Figure 2}

(a) The region of Galicia within Spain. The four background colours corresponds to provinces. The nodes in yellow, labelled with their respective names, represent the seven main cities. In this figure, it is also 
represented the main road networks, i.e. motorways/highways (red lines) and railways (yellow lines). (b) The sample study areas analyzed in section 5 are located and bounded by the red boxes. Note: The designations employed and the presentation of the material on this map do not imply the expression of any opinion whatsoever on the part of Research Square concerning the legal status of any country, territory, city or area or of its authorities, or concerning the delimitation of its frontiers or boundaries. This map has been provided by the authors.

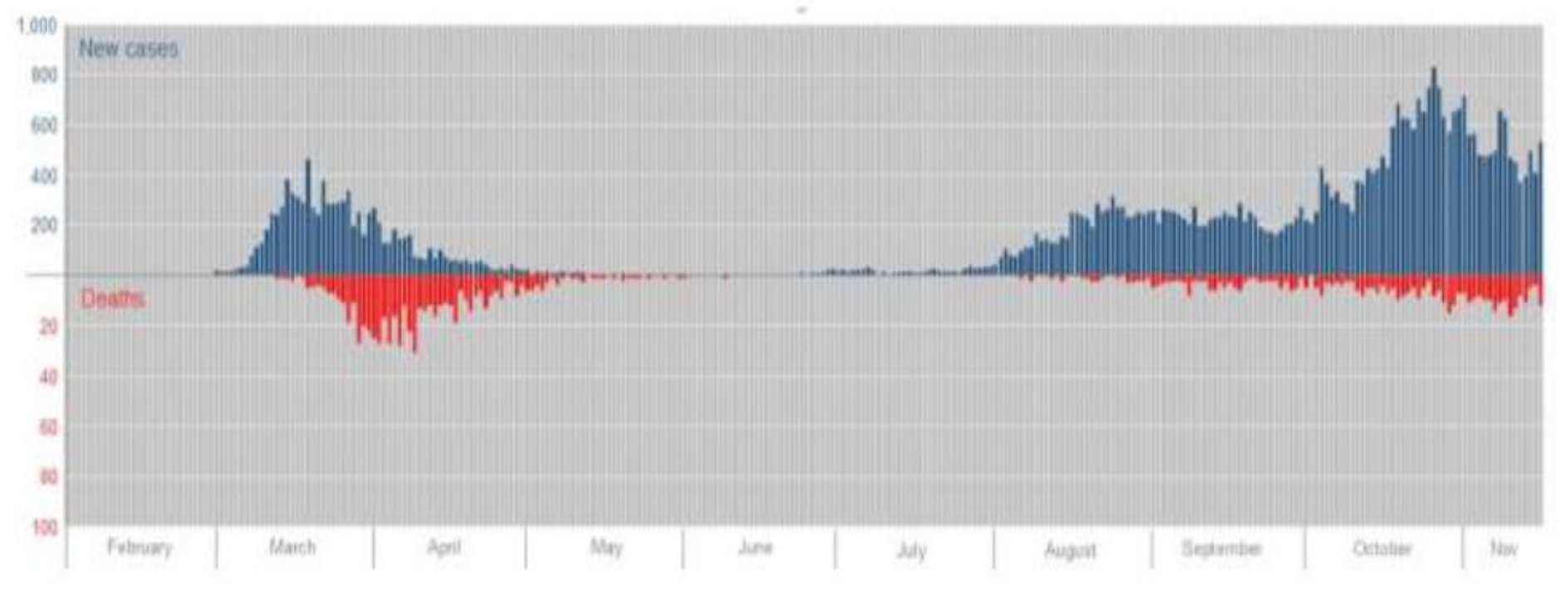

\section{Figure 3}

Number of reported cases and deaths from CoVID-19 in Spain since the beginning of the pandemic (31st January) until 15th November. Reported cases are shown in blue (Y-axis) and deaths in red (Y-axis inverted).

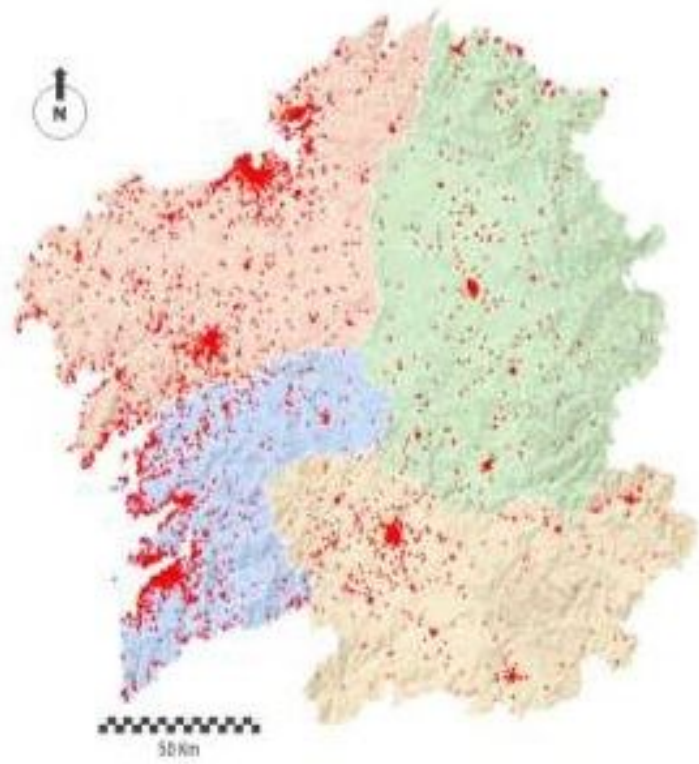

(a)

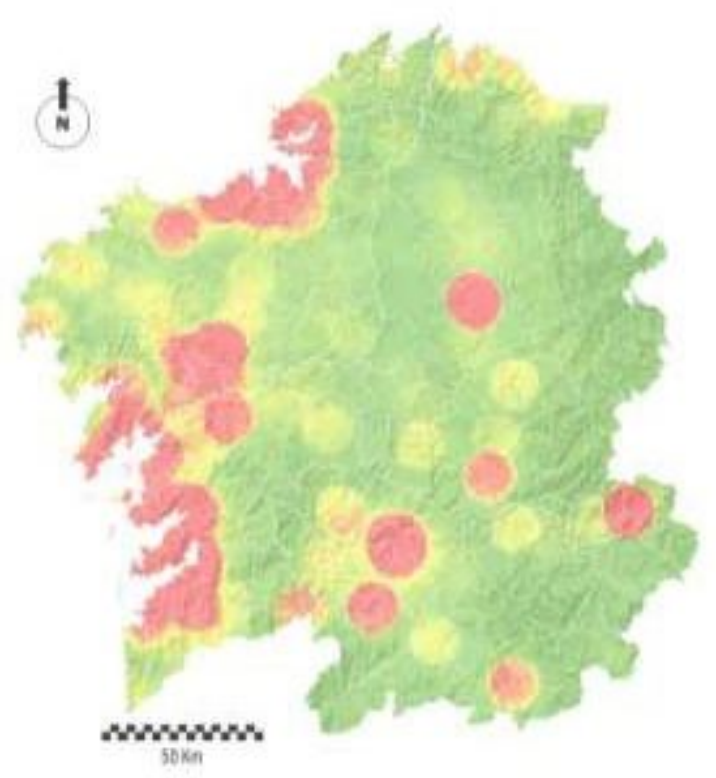

(b) 


\section{Figure 4}

Mapping COVID-19 cases officially reported in this region. (a) Representation of the most fine-grained level of detail. In this map, each single red dot corresponds to a reported case, which is spatially located based on the private address. (b) Mapping using a heat map, where areas with the highest point densities corresponds to the areas in red. Raster composed of 358 columns and 323 rows, with a cell size $1000 \mathrm{x}$ 1000. Note: The designations employed and the presentation of the material on this map do not imply the expression of any opinion whatsoever on the part of Research Square concerning the legal status of any country, territory, city or area or of its authorities, or concerning the delimitation of its frontiers or boundaries. This map has been provided by the authors.

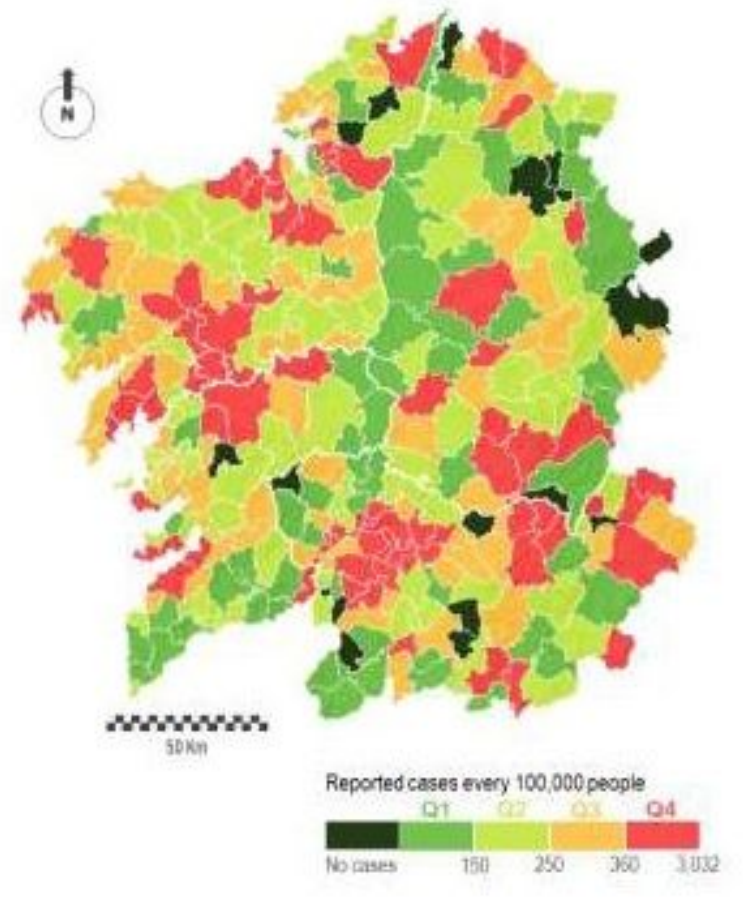

(a)

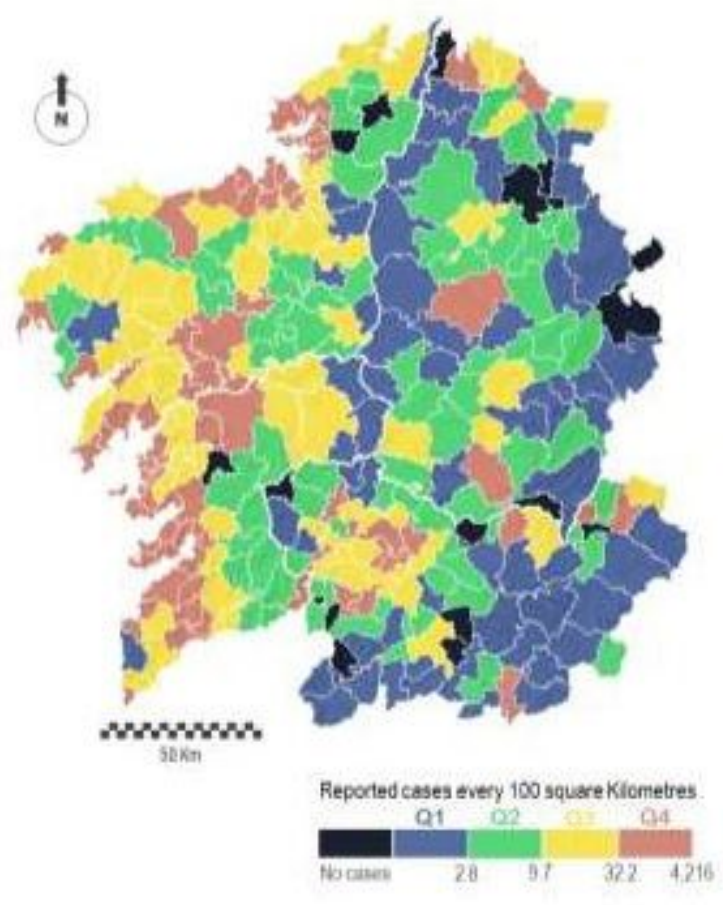

(b)

\section{Figure 5}

Mapping COVID-19 cases officially reported at a local scale of aggregation (municipalities). (a) Number of cases per 100,000 inhabitants. (b) Number of cases per $100 \mathrm{~km} 2$. In both cases, the intervals are distributed in regular quartiles. Note: The designations employed and the presentation of the material on this map do not imply the expression of any opinion whatsoever on the part of Research Square concerning the legal status of any country, territory, city or area or of its authorities, or concerning the delimitation of its frontiers or boundaries. This map has been provided by the authors. 


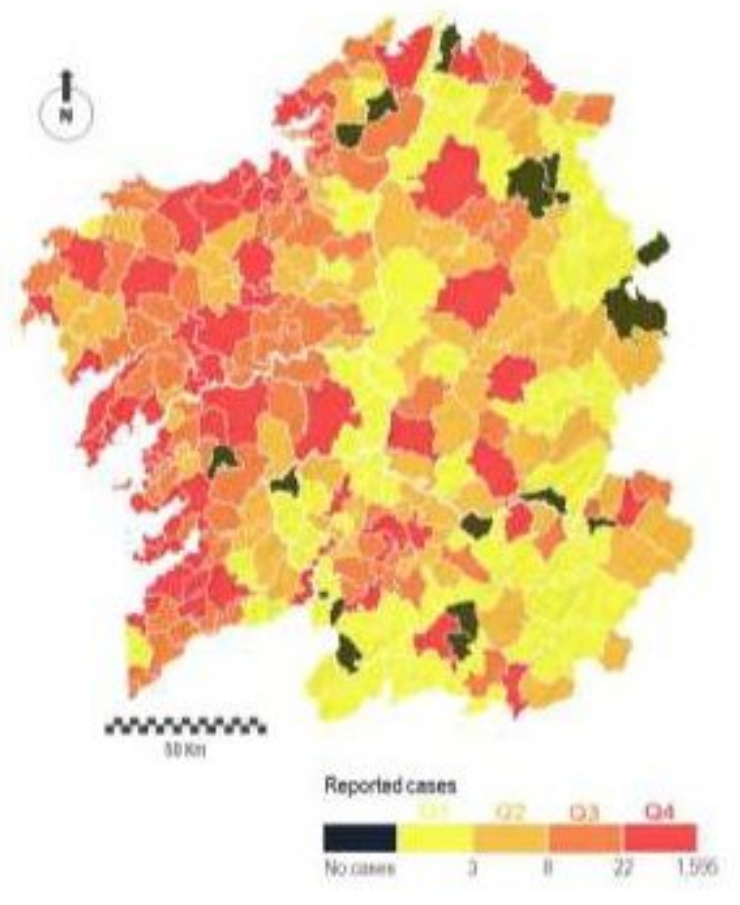

(a)

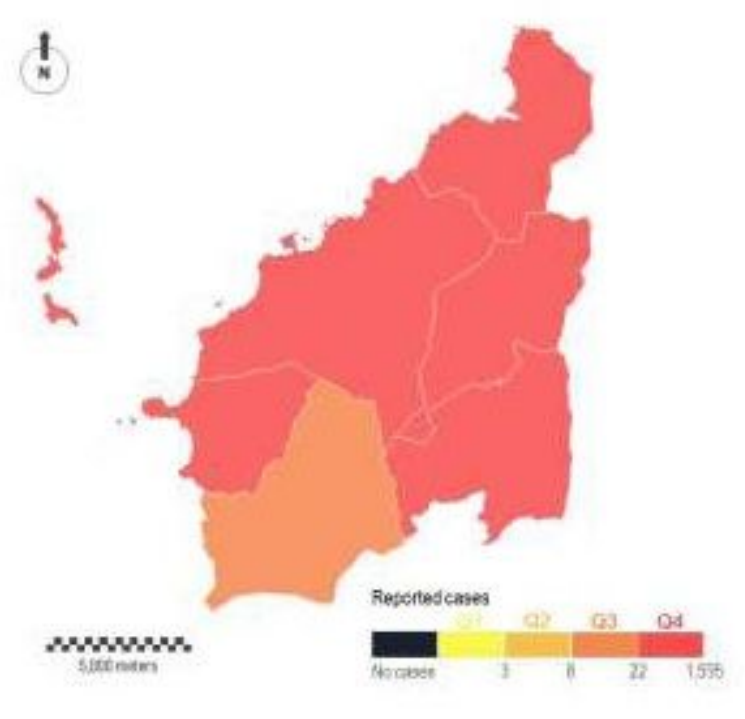

(b)

\section{Figure 6}

Number of CoVID-19 cases officially reported at a local scale of aggregation (municipalities). (a) Mapping data for the whole region. (b) Mapping data for a small case study located in the region of Vigo. Value intervals are distributed in regular quartiles. Note: The designations employed and the presentation of the material on this map do not imply the expression of any opinion whatsoever on the part of Research Square concerning the legal status of any country, territory, city or area or of its authorities, or concerning the delimitation of its frontiers or boundaries. This map has been provided by the authors. 


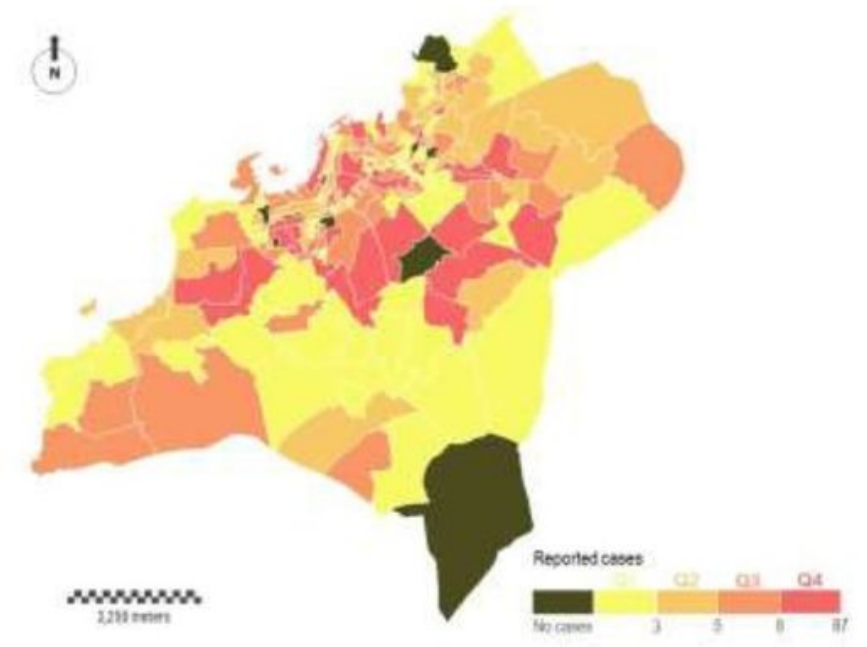

(a)

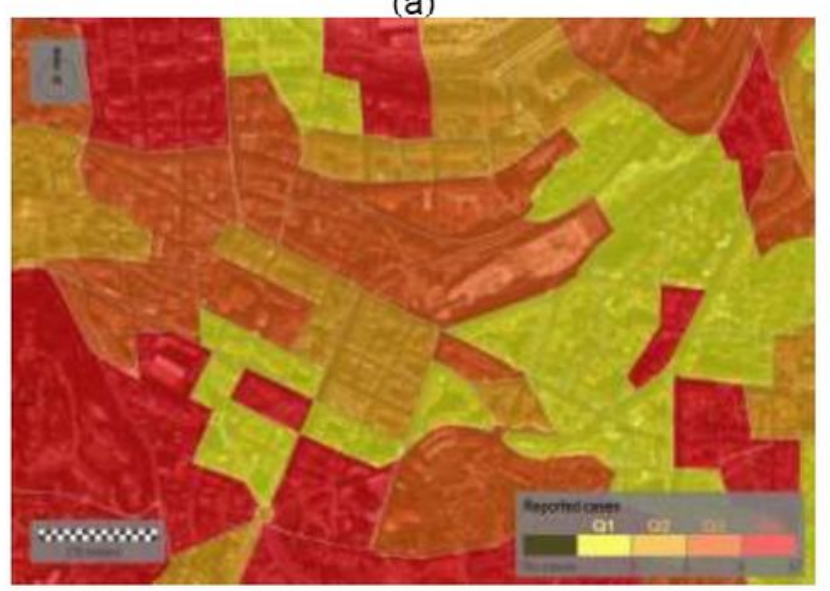

(b)

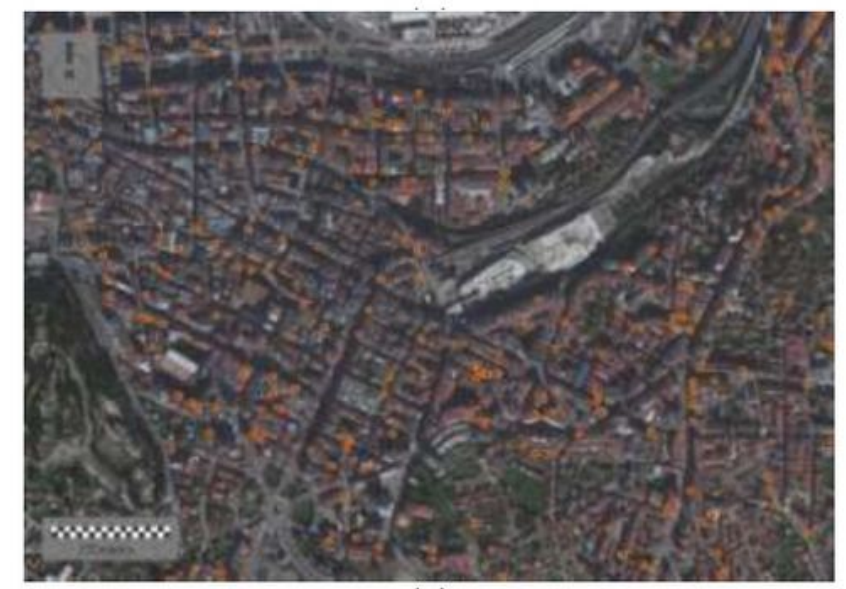

(c)

\section{Figure 7}

(a) Number of COVID-19 cases officially reported at an intermediate scale of aggregation (census districts) in the municipality of Vigo. Value intervals are distributed in regular quartiles. (b) Zooming into a specific area in the downtown of Vigo. (c) Disaggregated representation of reported cases in the same area. Note: The designations employed and the presentation of the material on this map do not imply the expression of any opinion whatsoever on the part of Research Square concerning the legal status of any 
country, territory, city or area or of its authorities, or concerning the delimitation of its frontiers or boundaries. This map has been provided by the authors.

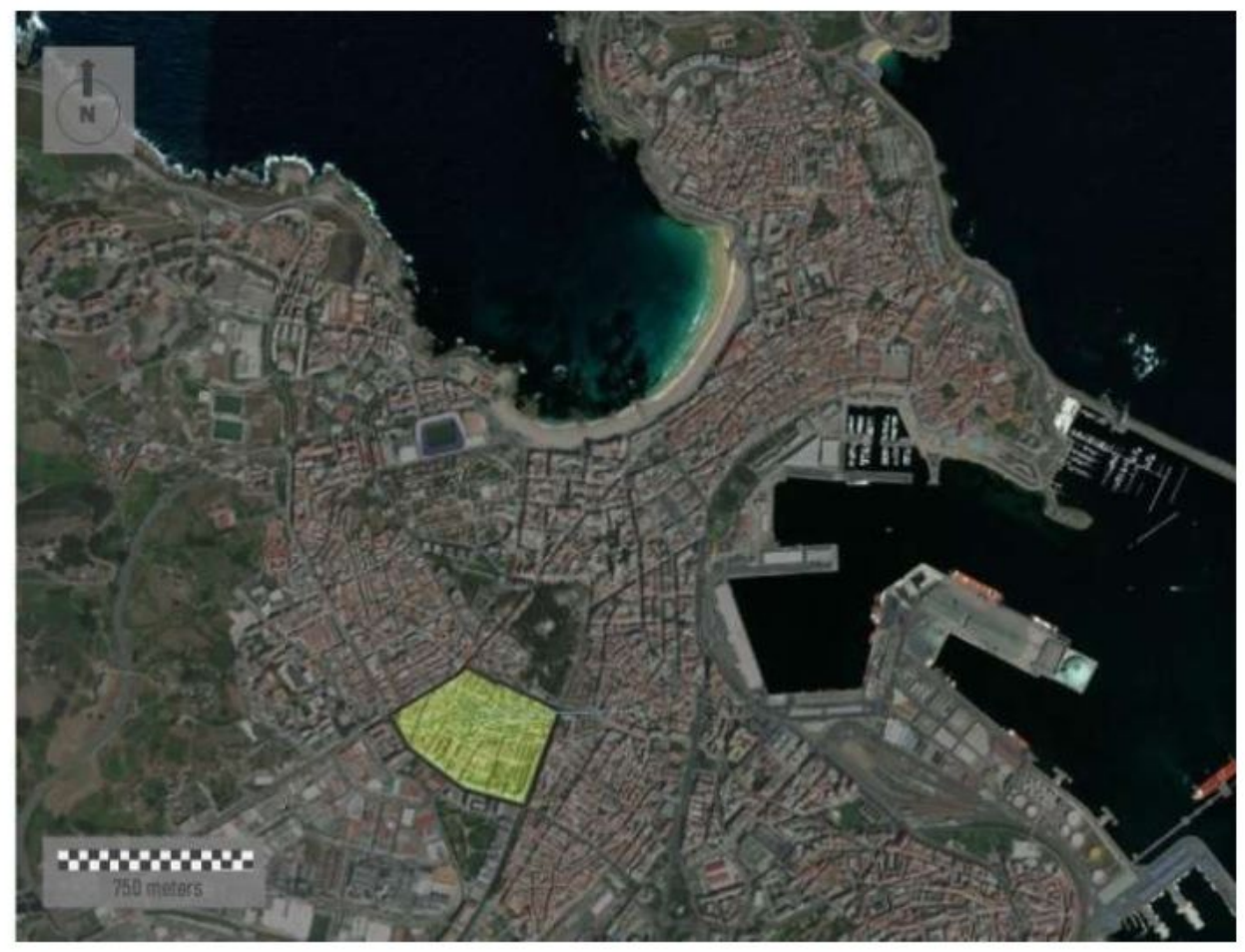

(a)

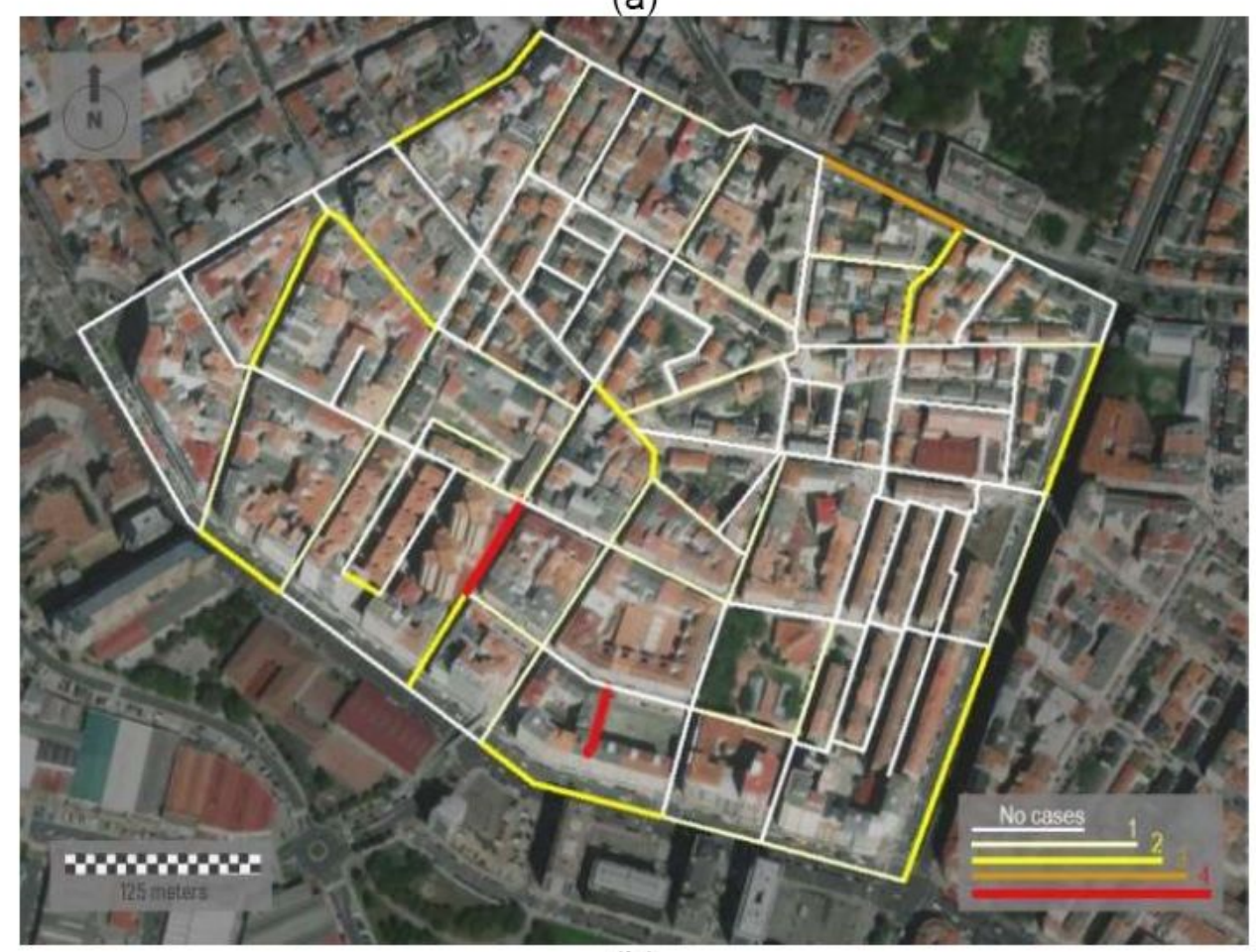

(b)

\section{Figure 8}

Number of COVID-19 cases officially reported in a specific area of A Coruña. (a) In yellow, we represent the location of this sample area within the city. (b) Data mapping of reported cases at the lowest scale of aggregation (street sections). Note: The designations employed and the presentation of the material on 
this map do not imply the expression of any opinion whatsoever on the part of Research Square concerning the legal status of any country, territory, city or area or of its authorities, or concerning the delimitation of its frontiers or boundaries. This map has been provided by the authors.

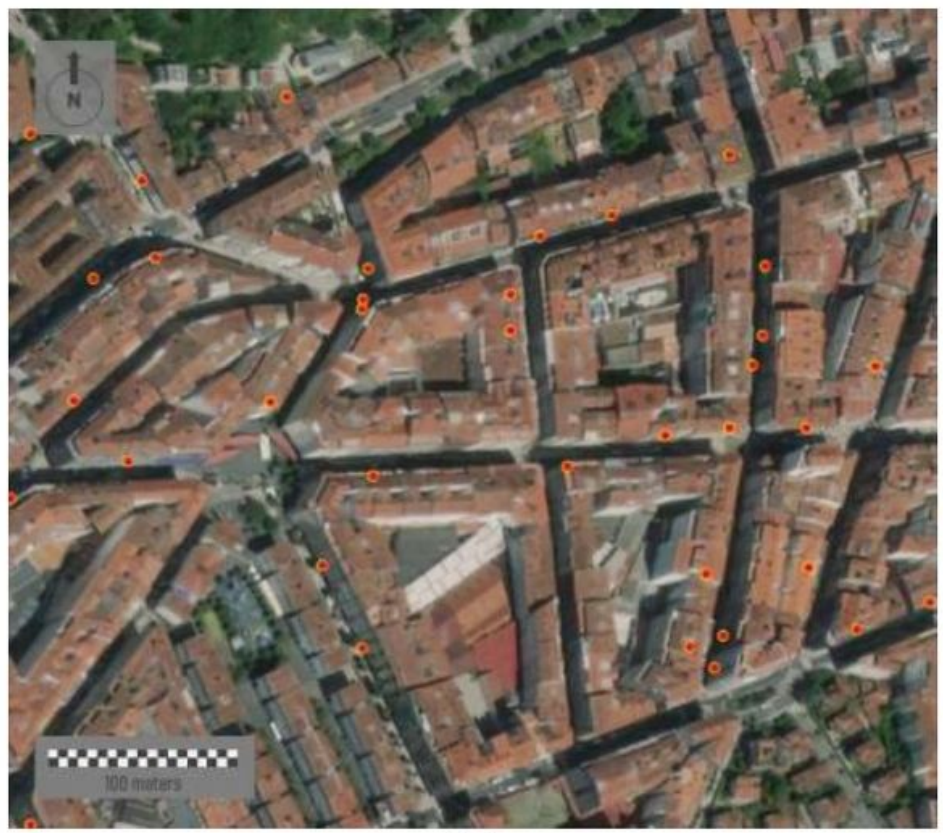

(a)

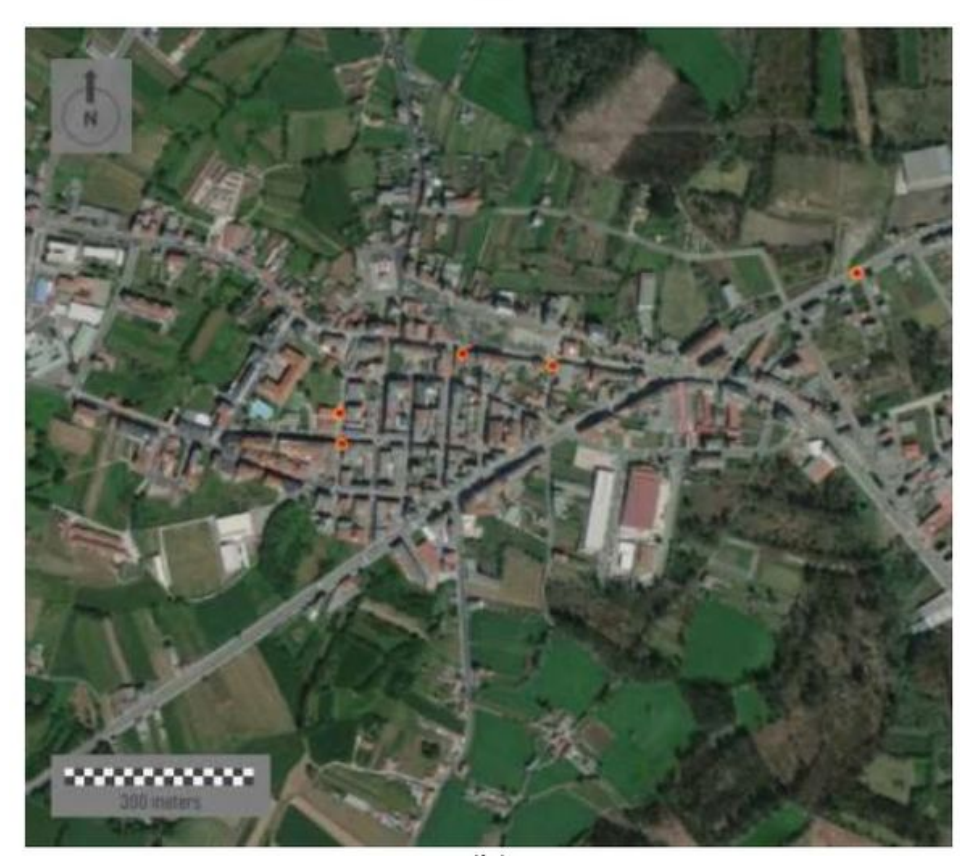

(b)

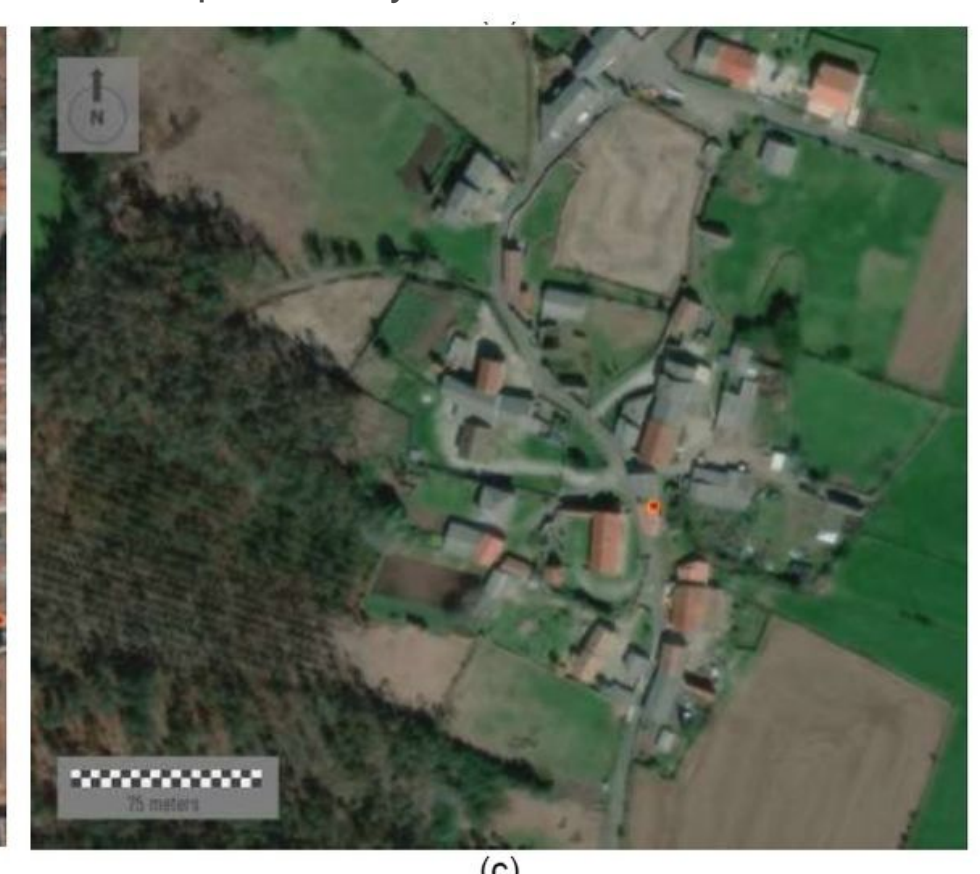

(c)

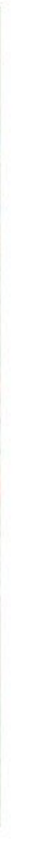

\section{(1)}


authorities, or concerning the delimitation of its frontiers or boundaries. This map has been provided by the authors.

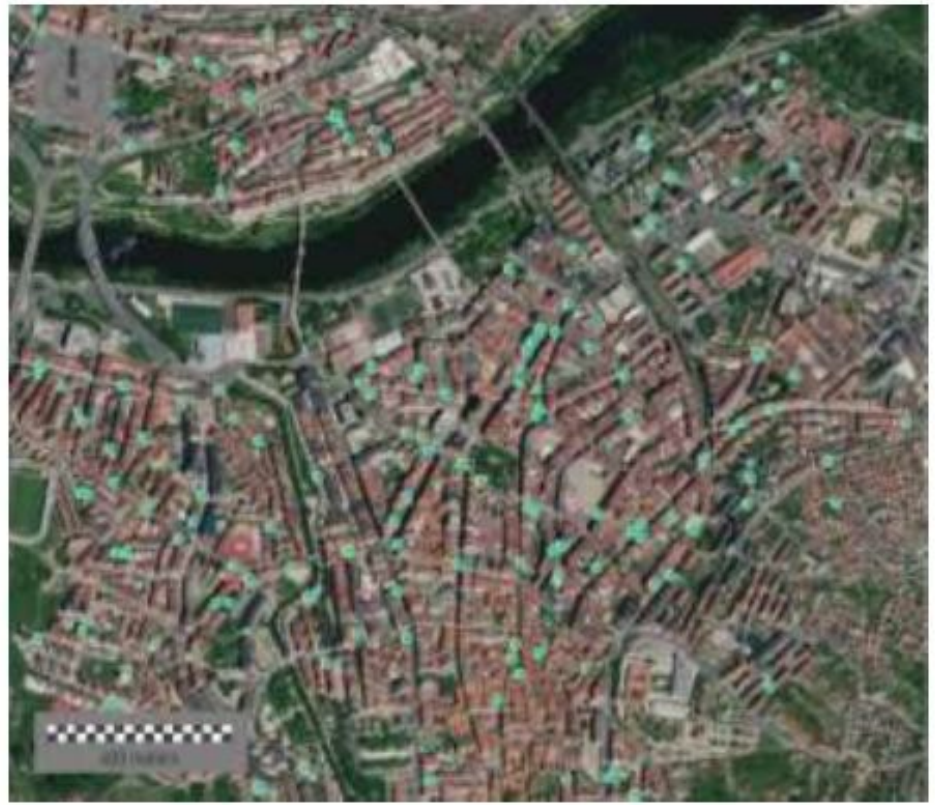

(a)

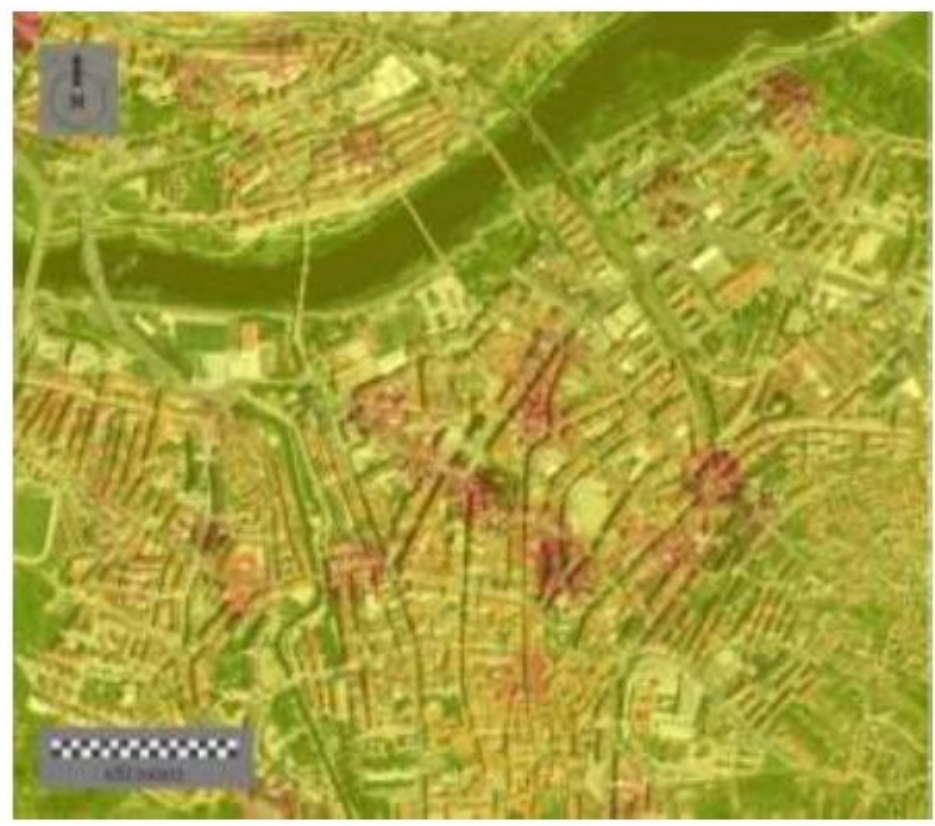

(c)

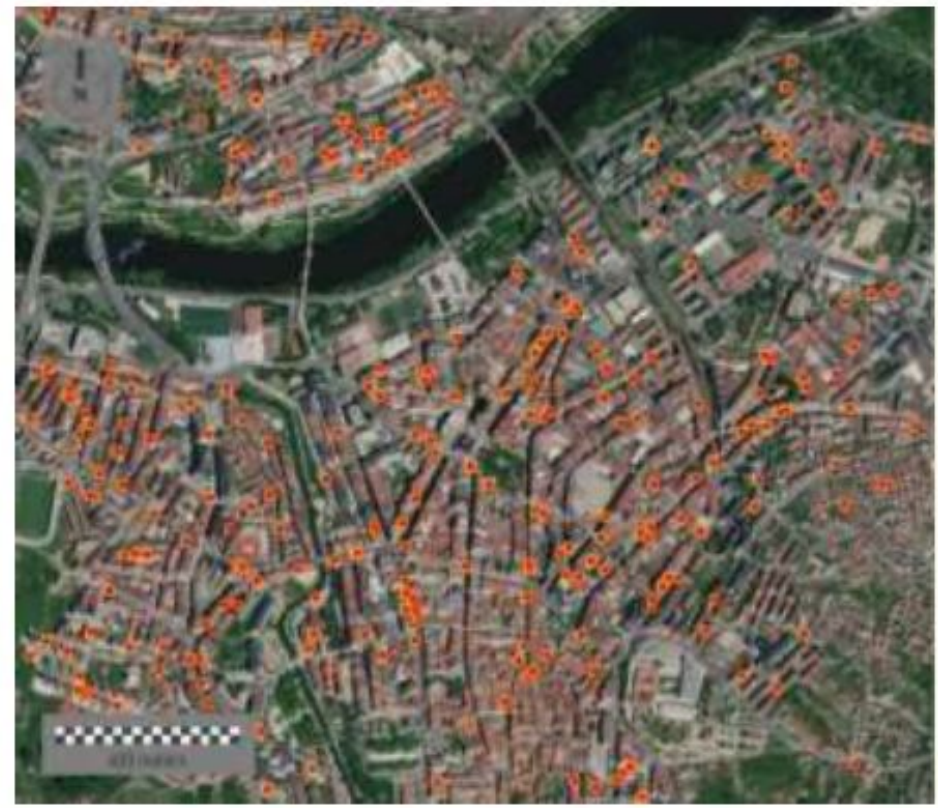

(b)

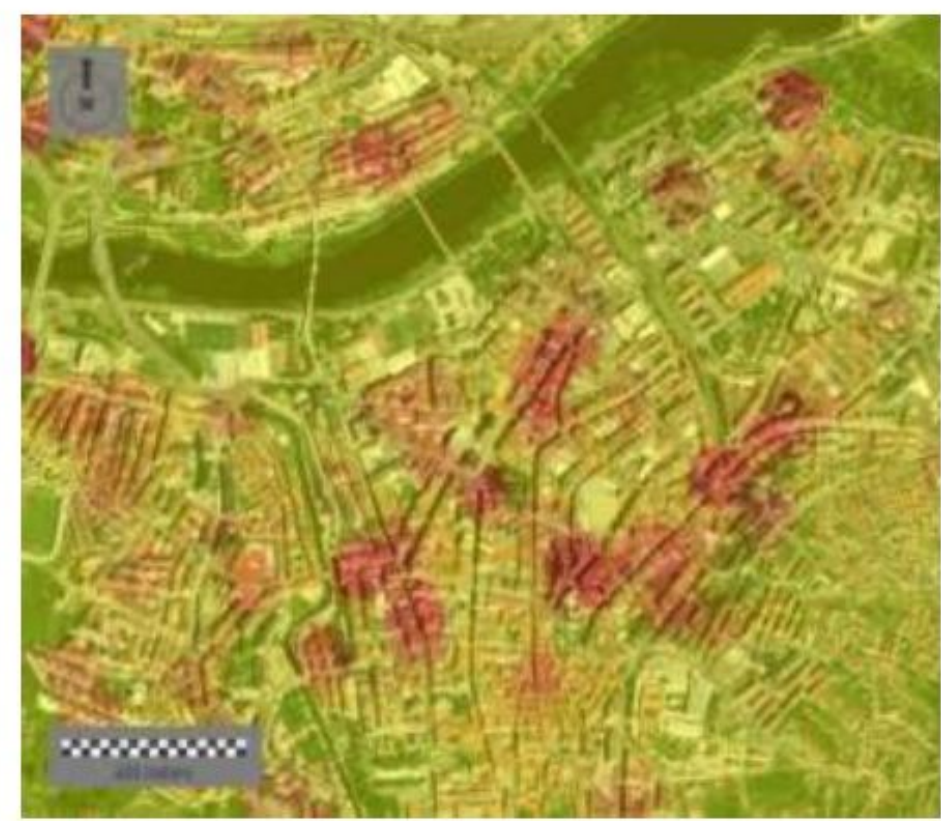

(d)

\section{Figure 10}

Temporal evolution of COVID-19 cases within the city of Ourense. (a) Disaggregated mapping of cases (a) on 1st April and (b) on 15th July. Heat map based on cases density for the above dates: (c) 1st April and (d) 15th July. The areas with the highest concentration of dots correspond to the areas in red. Raster composed of 272 columns and 356 rows, with a cell size $10 \times 10$. Note: The designations employed and the presentation of the material on this map do not imply the expression of any opinion whatsoever on 
the part of Research Square concerning the legal status of any country, territory, city or area or of its authorities, or concerning the delimitation of its frontiers or boundaries. This map has been provided by the authors.

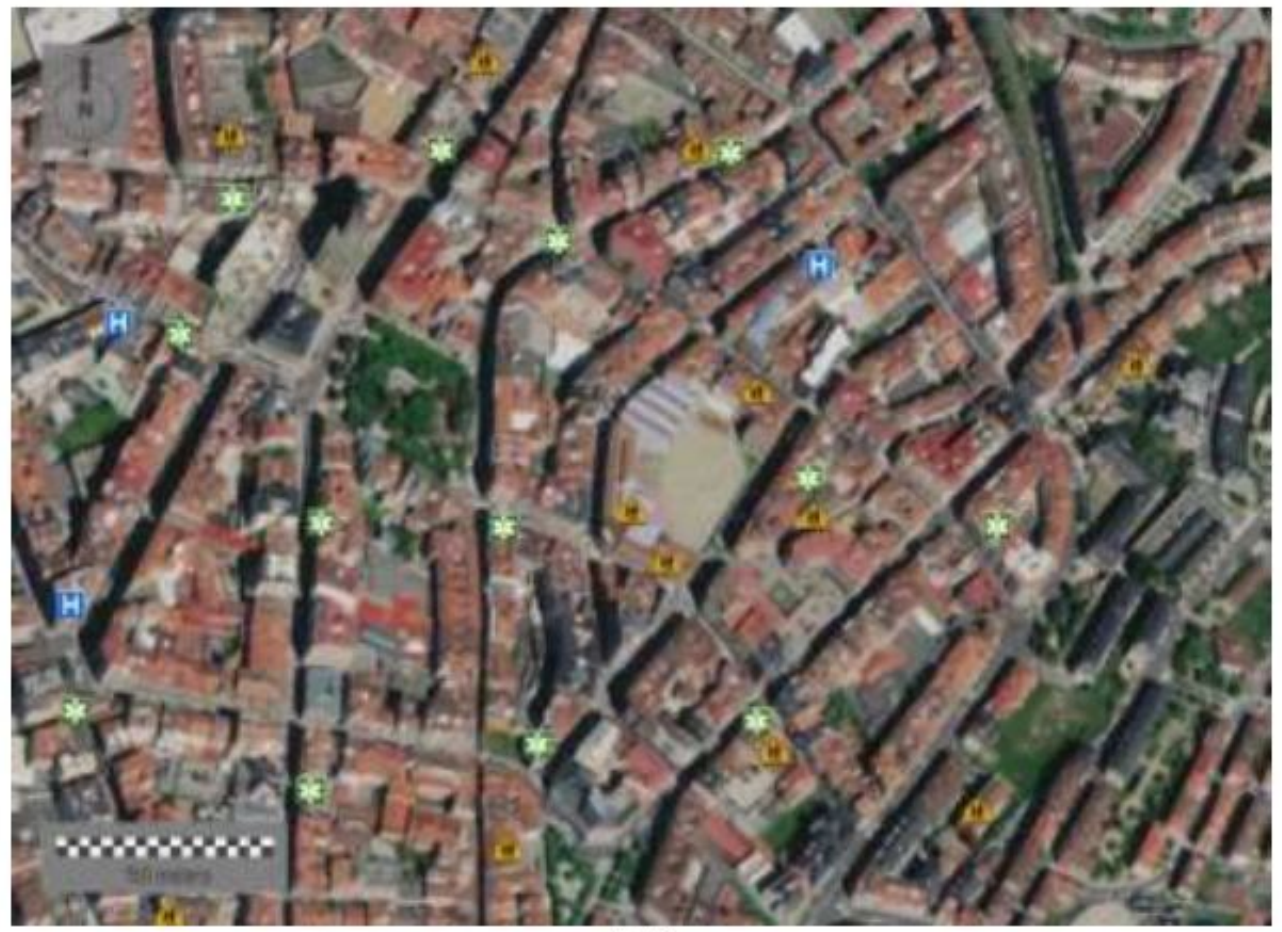

(a)

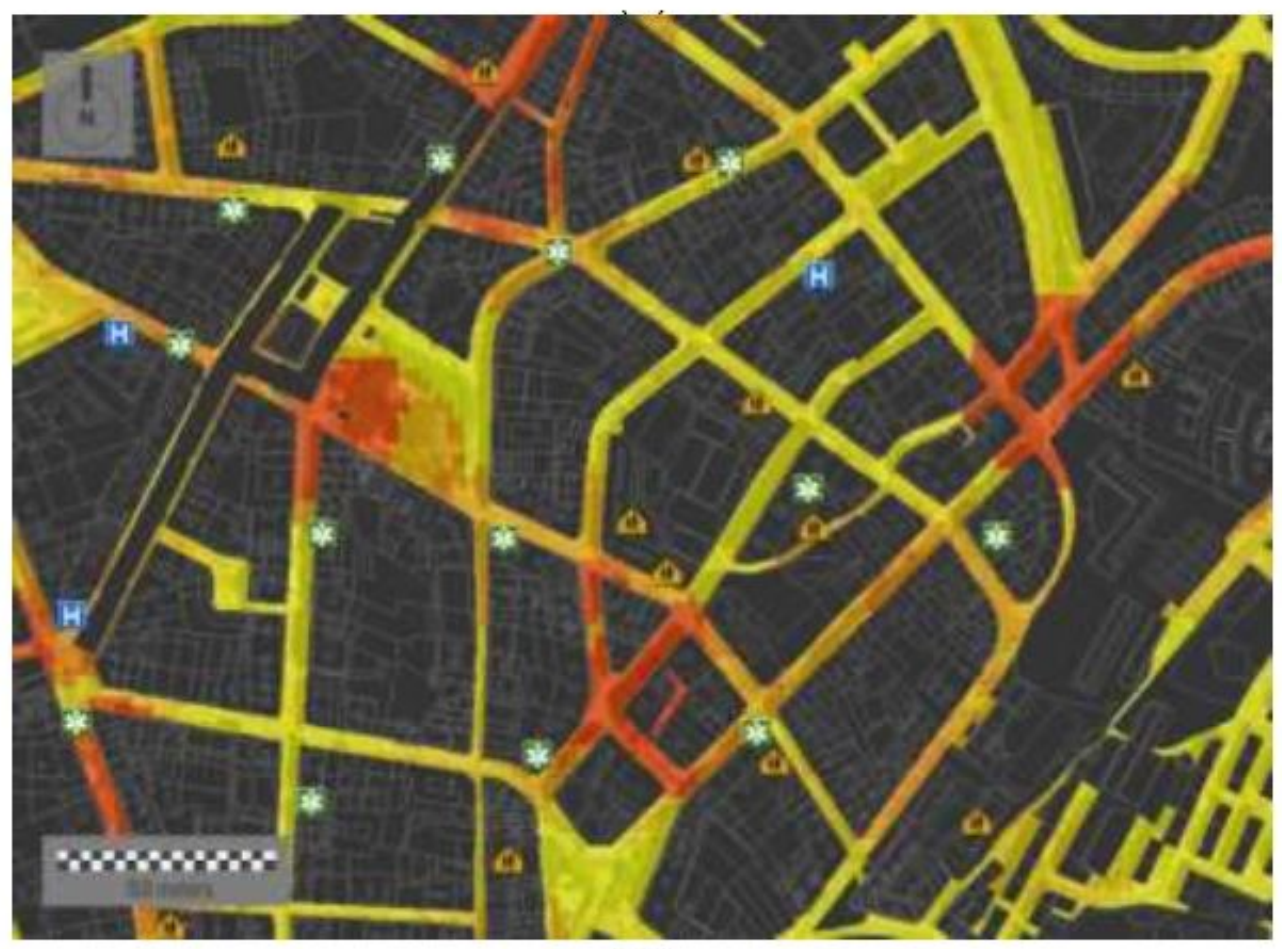

(b)

\section{Figure 11}

Analysis of the incidence of COVID-19 in a sample area of Ourense's downtown. (a) Aerial image of this sample area. (b) Mapping those areas with the highest concentration of cases within the public space, i.e. 
streets and parks. The rest of the urban space is represented with a grey dark colour. To add further value to these maps, we overlap a series of public facilities (such as educational centres, pharmacies, health centres) that potentially influence the spread of the virus. Raster composed of 272 columns and 356 rows, with a cell size $10 \times 10$. Note: The designations employed and the presentation of the material on this map do not imply the expression of any opinion whatsoever on the part of Research Square concerning the legal status of any country, territory, city or area or of its authorities, or concerning the delimitation of its frontiers or boundaries. This map has been provided by the authors. 